\title{
Japanese Clinical Practice Guideline for Diabetes 2016
}

\author{
Masakazu Haneda $^{1} \cdot$ Mitsuhiko Noda $^{2} \cdot$ Hideki Origasa $^{3} \cdot$ Hiroshi Noto $^{4} \cdot$ Daisuke Yabe $^{5} \cdot$ Yukihiro Fujita $^{1}$. \\ Atsushi Goto $^{6} \cdot$ Tatsuya Kondo $^{7} \cdot$ Eiichi Araki ${ }^{7}$
}

Received: 12 January 2018 / Published online: 27 March 2018

(C) The Japan Diabetes Society 2018

Keywords Diabetes $\cdot$ Guideline $\cdot$ Diagnosis $\cdot$ Treatment

\section{Preface}

Since its inception in 2004, the "Clinical Practice Guidelines for the Treatment of Diabetes" has attempted to promote evidence-based, rational, efficient and standardized clinical practice for diabetes in Japan and has undergone revisions every 3 years. Thus, the current edition represents the fifth revision.

Of note, in recent years, breakthroughs have been made in the management of diabetes and its complications, which include the approval of glucose-lowering agents with novel mechanisms of action for clinical use and the introduction and adoption of novel diagnostic and therapeutic modalities, such as continuous glucose monitoring (CGM) and sensoraugmented insulin pumps (SAP), in clinical practice. Again,

This article is based on the "Japanese Clinical Practice Guideline for Diabetes 2016" (ISBN978-4-524-25857-4), which was published in Japanese by Nankodo Co., Ltd. (@ The Japan Diabetes Society (JDS), 2016) and has been jointly published in Journal of Diabetes Investigation (the official journal of the Asian Association for the Study of Diabetes: https://doi.org/10.1111/ jdi.12810) and Diabetology International (the official English journal of JDS).

Masakazu Haneda

jds-journal@jds.or.jp

Asahikawa Medical University, Asahikawa, Japan

2 Saitama Medical University, Saitama, Japan

3 University of Toyama, Toyama, Japan

4 St Luke's International Hospital, Tokyo, Japan

5 Department of Diabetes, Endocrinology and Nutrition, Kyoto University Graduate School of Medicine, Kyoto, Japan

6 Center for Public Health Sciences, National Cancer Center, Tokyo, Japan

7 Department of Metabolic Medicine, Kumamoto University, Kumamoto, Japan renewed interest in diabetes-associated diseases has led to the accumulation of new evidence, as well as new developments at the Japan Diabetes Society (JDS), such as ongoing efforts directed toward the revision of the Classification of Diabetic Nephropathy, ensuring consistency between glucose metabolic disorders and the diagnostic criteria for diabetes in pregnancy, and establishing glycemic control goals for older patients with diabetes. Indeed, these developments have gone hand in hand with the emergence of high-quality evidence from numerous studies conducted in countries throughout the world, including Japan. Thus, the current edition aims to incorporate these new insights and findings, as well as new lines of evidence, in diabetes treatment.

With regard to the revision of the guideline, the current edition has newly adopted a clinical question (CQ)/question (Q) format, instead of the "statement" format of the earlier editions, in the hope that this new format will help improve the ease of use of the guidelines in clinical practice. The grades of recommendation have also been revised.

It is hoped that the current guidelines will serve as a guide to implementing evidence-based medicine (EBM) for diabetes in Japan and thereby contribute to prolonging the longevity and improving the quality of life (QOL) of patients with diabetes. 


\section{Methods for developing the "Japanese Clinical Practice Guideline for Diabetes 2016"}

The present guideline, which is divided into 21 chapters, consists of important statements intended to assist in clinical practice, which are also intended as recommendations. These statements were developed separately as general questions and clinical questions based on published clinical evidence as well as expert consensus.

This guideline offers key recommendations for clinical practice that are supported by scientific evidence from published studies. Studies of interest were obtained by a systematic search of the English and Japanese literature. The electronic database used for literature search included at least MEDLINE and the Japanese ICHUSHI database (http:// www.jamas.or.jp/). The search strategies used were developed by each author. The studies of interest were critically appraised by the authors to determine their relevance to the statements of the guideline and whether they were worth citing. Each study was assigned a level of evidence using the approach described in Table 1.

Each statement for the CQs was assigned a grade of recommendation based on the total body of evidence as well as the risk-benefit balance, value, patient preferences, cost, and resources. Statements were graded as A (strongly recommended) or B (recommended), followed by the agreement rate among authors. Grade A or B by consensus reflects a recommendation based solely on the consensus of professionals and indicates that the recommendation was adopted with $a \geq 70 \%$ agreement rate among the authors.
A summary table, including an identifier, the research design, the level of evidence and population, methods, and results of the cited articles was attached at the end of each chapter in the original Japanese version. (The Japan Diabetes Society: Japanese Clinical Practice Guideline for Diabetes 2016. Tokyo: Nankodo, 2016.) Scientific reports supporting a statement were cited as "References" and additional guidelines or review articles were listed as "Additional reference materials".

The guideline will be reviewed every 3 years, as there will be considerable advances in clinical research and practice that will require a re-evaluation of the scientific evidence as it becomes available. All potential conflicts of interest were disclosed by authors.

\section{Guideline for the diagnosis of diabetes mellitus}

\section{Q1-1 How is diabetes diagnosed? (Fig. 1)}

- The diagnosis of diabetes mellitus should be as comprehensive as possible. It is confirmed by the presence of chronic hyperglycemia, and by the presence of other factors, such as associated symptoms, clinical laboratory findings, a family history of diabetes, and the patient's body weight history (1-5). For the diagnosis of diabetes, either of the following approaches is to be followed:

(1) Two assessments of the diabetic type in each patient (one blood glucose test is mandatory).
Table 1 Criteria for assigning levels of evidence to publications of interest

\begin{tabular}{ll}
\hline Level of evidence & Type of evidence \\
\hline $1+$ & High-quality andomized controlled trials (RCTs) \\
& Meta-analysis or systematic review of trials with level $1+$ \\
& RCTs that fail to meet level $1+$ evidence \\
& Meta-analysis or systematic review of trials with level 1 \\
& Prospective cohort studies, or meta-analysis or systematic review of them \\
& Pre-specified sub-analyses of RCTs \\
& Non-randomized controlled trials \\
& Self-controlled (before-after) studies \\
& Retrospective cohort studies \\
& Case-control studies, or meta-analysis or systematic review of them \\
& Post hoc sub-analyses of RCTs \\
Cross-sectional studies & Case-series \\
\hline
\end{tabular}

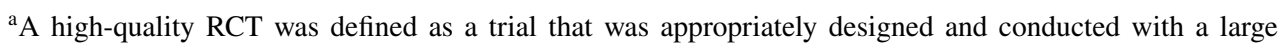
sample size and a clearly specified randomization scheme, involving double masking and a high follow-up rate 


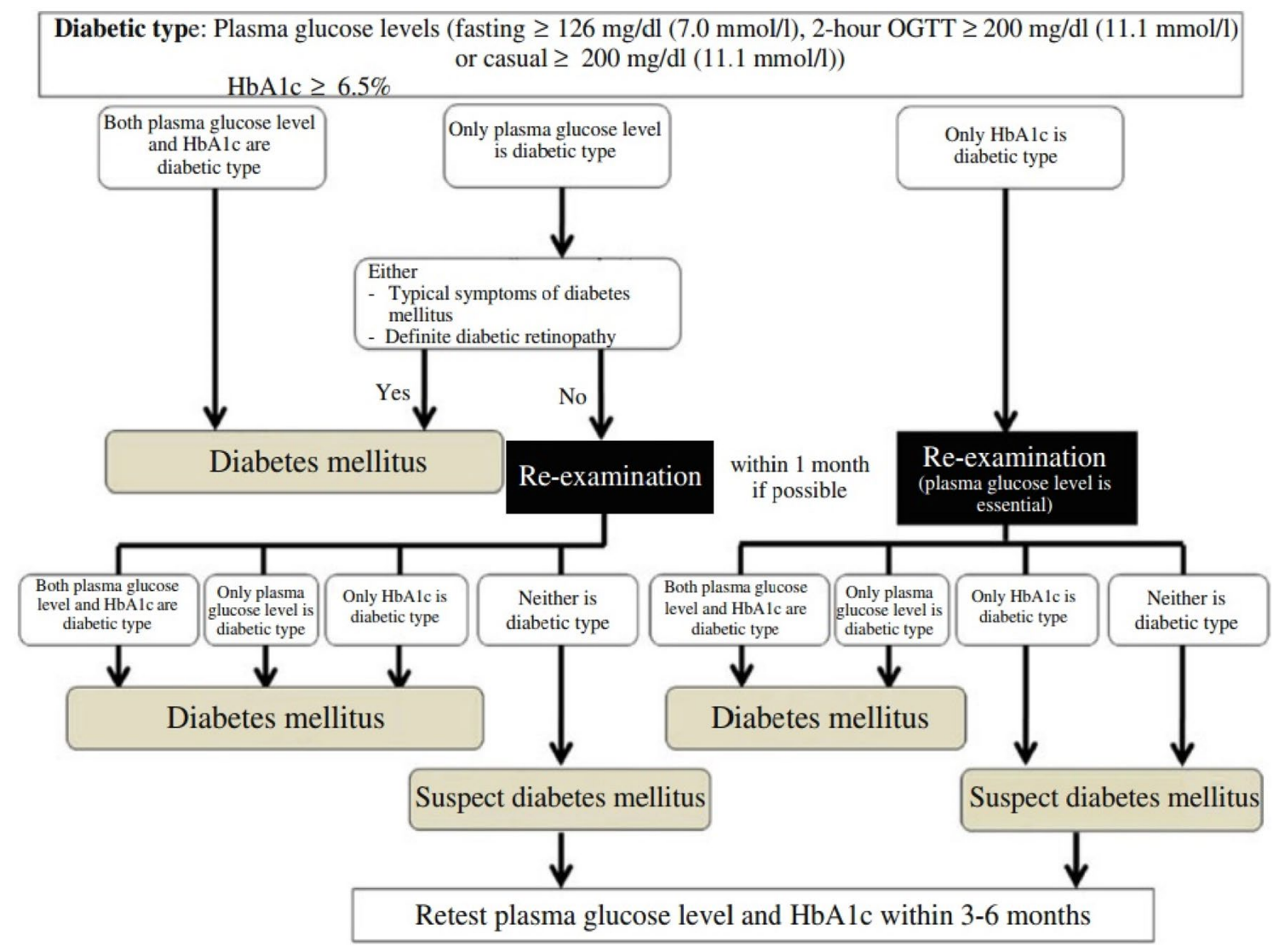

Fig. 1 Flow chart outlining the steps in the clinical diagnosis of diabetes mellitus. OGTT oral glucose tolerance test

Fig. 2 The categories of glycemia as indicated by fasting plasma glucose levels and $75 \mathrm{~g}$ OGTT results

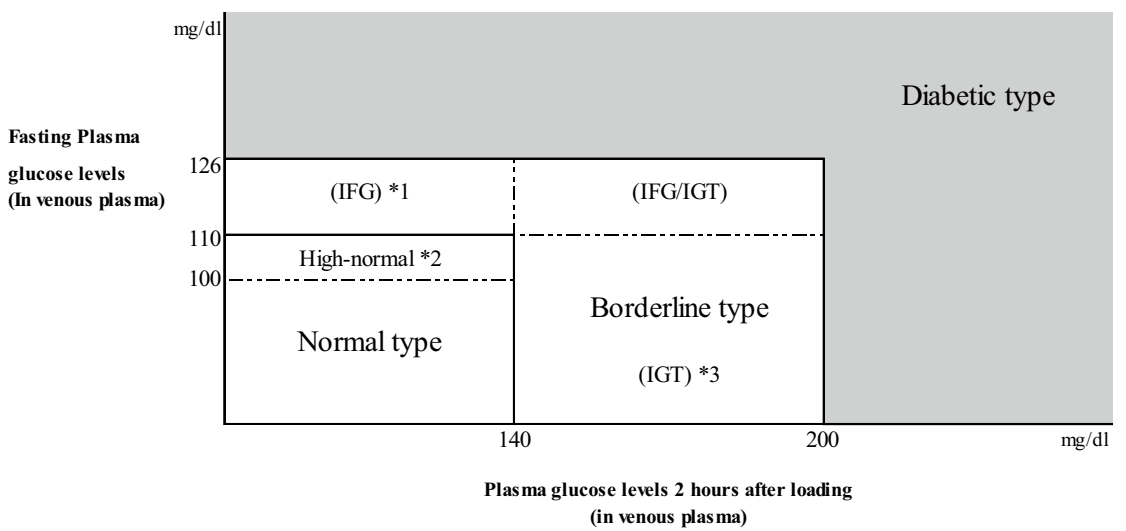

* 1 The impaired fasting glucose (IFG) category represents cases of fasting plasma glucose levels of 110$125 \mathrm{mg} / \mathrm{dl}(6.1 \sim 7.0 \mathrm{mmol} / \mathrm{L})$ and two-hour plasma glucose levels of $<140 \mathrm{mg} / \mathrm{dl}(7.8 \mathrm{mmol} / \mathrm{L}) \mathrm{in} \mathrm{a} 75 \mathrm{~g}$ OGTT (WHO).

However, in the ADA criteria, IFG is defined as a fasting plasma glucose levels of $100-125 \mathrm{mg} / \mathrm{dl}$ (5.6-7.0 mmol/L), and only FPG is used for the determination of IFG.

* 2 Fasting plasma glucose levels of 100-109 mg/dl(5.6-6.1 mmol/L) are within the normal limits, but are considered to be "high-normal". Because patients with a high-normal glucose level are at risk of developing diabetes and include cases with various degrees of impaired glucose tolerance, the performance of an OGTT is desirable.

*3 The category was adopted by the WHO in the diagnostic criteria for diabetes mellitus, and represents cases with fasting plasma glucose levels of $<126 \mathrm{mg} / \mathrm{dl}$ and two-hour plasma glucose levels of 140-199 $\mathrm{mg} / \mathrm{dl}(7.8-11.1 \mathrm{mmol} / \mathrm{L}$ in a $75 \mathrm{~g}$ OGTT. 
Table 2 Etiological classification of diabetes mellitus and glucose metabolism disorders
I. Type 1 (destruction of pancreatic $\beta$-cells, usually leading to absolute insulin deficiency)
A. Autoimmune
B. Idiopathic

II. Type 2 (ranging from predominantly insulin secretory defect to predominantly insulin resistance with varying degrees of insulin secretory defect)

III. Due to other specific mutation or diseases

A. Those in which specific mutations have been identified as a cause of genetic susceptibility

(1) Genetic abnormalities of pancreatic $\beta$-cell function

(2) Genetic abnormalities of insulin action

B. Those associated with other diseases or conditions

(1) Diseases of exocrine pancreas

(2) Endocrine disease

(3) Liver disease

(4) Drug- or chemical-induced

(5) Infections

(6) Rare forms of immune-mediated diabetes

(7) Various genetic syndromes often associated with diabetes

IV. Gestational diabetes mellitus

The occurrence of diabetes specific complications has not been confirmed in some of these conditions. Those that cannot currently be classified as any of the above are considered unclassifiable
(2) One assessment of the diabetic type (with mandatory blood glucose testing) along with the presence of chronic hyperglycemic symptoms*. (*typical symptoms of chronic hyperglycemia (e.g., dry mouth, polyposia, polyuria, body weight loss, or diabetic retinopathy).

(3) Evidence of a prior diagnosis of "diabetes".

\section{Q1-2 How is hyperglycemia assessed? (Fig. 2)}

- Patients are to be classified into the normal type, borderline type, or diabetic type, based on the combination of fasting and 2-h post-75 g oral glucose tolerance test (OGTT) glucose values.

- Patients whose fasting glucose values are 100-109 mg/ $\mathrm{dL}(5.6-6.1 \mathrm{mmol} / \mathrm{L})$ are classified into the "high normal" category as part of the normal type [6].

- The OGTT is to be proactively considered in high-risk individuals (i.e., those who are suspected to have diabetes or the borderline type, those whose fasting glucose values are shown to be "high-normal", those with HbA1c values of $\geq 5.6 \%$, those with obesity or dyslipidemia, and those with a strong family history of diabetes [5]).
- At present, HbA1c values measured by point-of-care testing (POCT) devices are not to be used for the diagnosis [5].

\section{Q1-3 How should individuals who are shown to be the diabetic type in an initial glucose/ HbA1c assessment but who not on subsequent assessments be managed?}

- When the diagnosis is not confirmed by repeated assessments, glucose measurements and OGTTs should be performed every 3-6 months to monitor their clinical course [5].

- If the glucose value on the initial assessment was found to be $\geq 200 \mathrm{mg} / \mathrm{dL}$ ( $11.1 \mathrm{mmol} / \mathrm{L})$ by a casual blood glucose measurement, it would be preferable to use other tests on the subsequent confirmatory assessments [5].

- In principle, confirmatory assessments should involve both HbA1c and blood glucose measurements. The diagnosis must be made with close attention given to their blood glucose values, particularly in patients with any disease or condition that is likely to result in disparity between the HbA1c level and the mean glucose value [5]. 


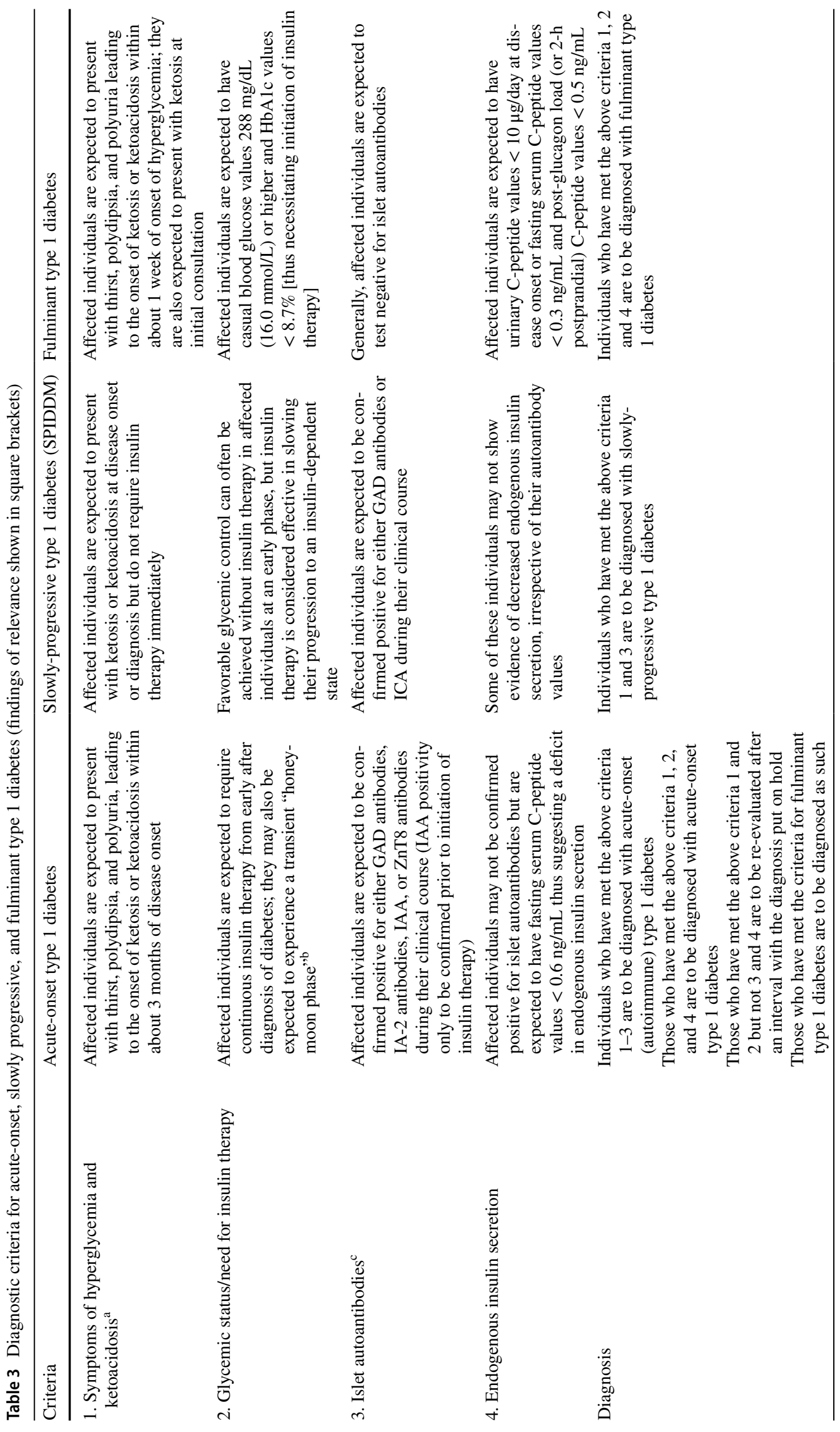




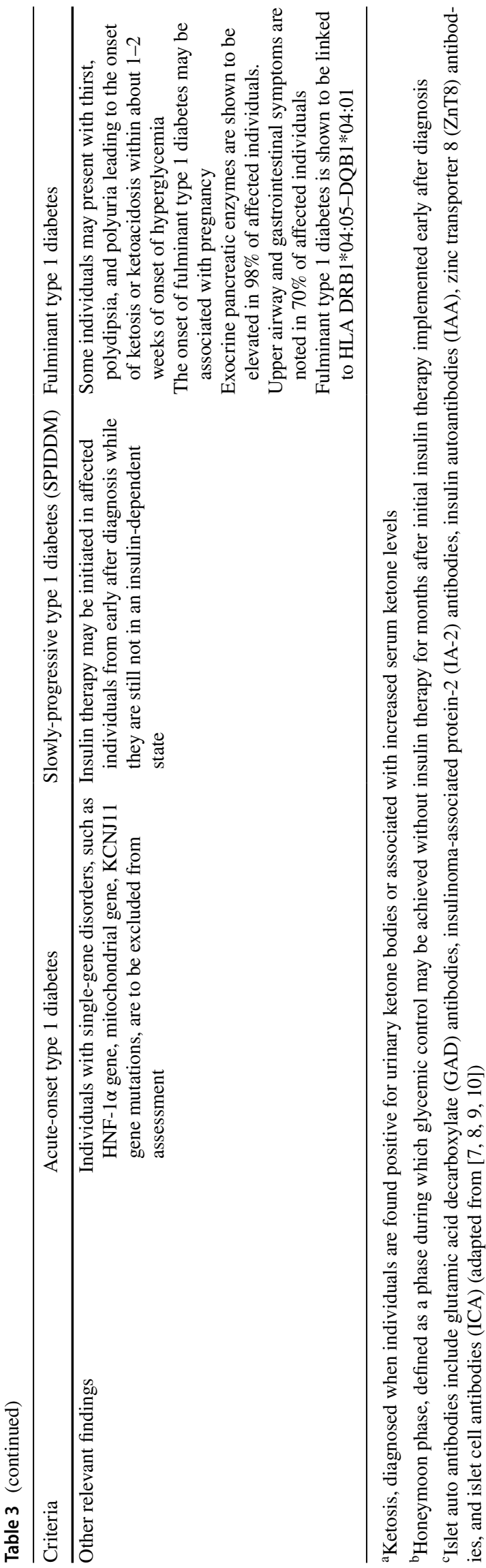

Q1-4 How is diabetes classified into its types? (Table 2)

- The classifications of diabetes are to be primarily described according to the etiology (mechanism), and additionally according to the pathophysiological state (stage) based on the insufficiency of insulin action (see Q1-7 for the relationship between their etiology and pathophysiology).

- Diabetes and other glucose metabolic disorders are to be classified into four categories: (I) type 1 diabetes, (II) type 2 diabetes, (III) other types due to specific pathophysiological mechanisms or diseases, and (IV) gestational diabetes (GDM). At present, all forms of diabetes or other glucose metabolic disorders that fail to be classified as any of the above are to be classified as "unclassifiable" [5].

- The etiological factors of patients should be assessed with attention to various types of clinical information such as the family history, age at the onset of diabetes and clinical course, physical characteristics, islet autoantibodies, human leukocyte antigen (HLA), insulin-secretory capacity/severity of insulin resistance, and genetic test results [5].

- Individual patients may have multiple etiological factors [5].

\section{Q1-5 How is type 1 diabetes (including acute, slowly progressive, and fulminant forms of type 1 diabetes) diagnosed? (Table 3)}

- Type 1 diabetes is classified by the etiology as (A) autoimmune and (b) idiopathic and also classified by the manner of the disease onset as acute, slowly progressive, and fulminant.

- Patients with acute type 1 diabetes are generally likely to develop ketosis or ketoacidosis within 3 months of the onset of hyperglycemia and required insulin therapy immediately [7].

- Patients with slowly progressive (insulin-dependent) type 1 diabetes do not develop ketosis or ketoacidosis and do not require insulin therapy immediately, although their diagnosis is established by a positive test for anti-GAD antibodies or islet cell antibodies (ICA) [8].

- Patients with fulminant type 1 diabetes frequently develop ketosis or ketoacidosis within 1 week of the onset of hyperglycemia, require insulin therapy immediately, and are characterized by having lower $\mathrm{HbAlc}$ values relative to their glucose values [9]. 


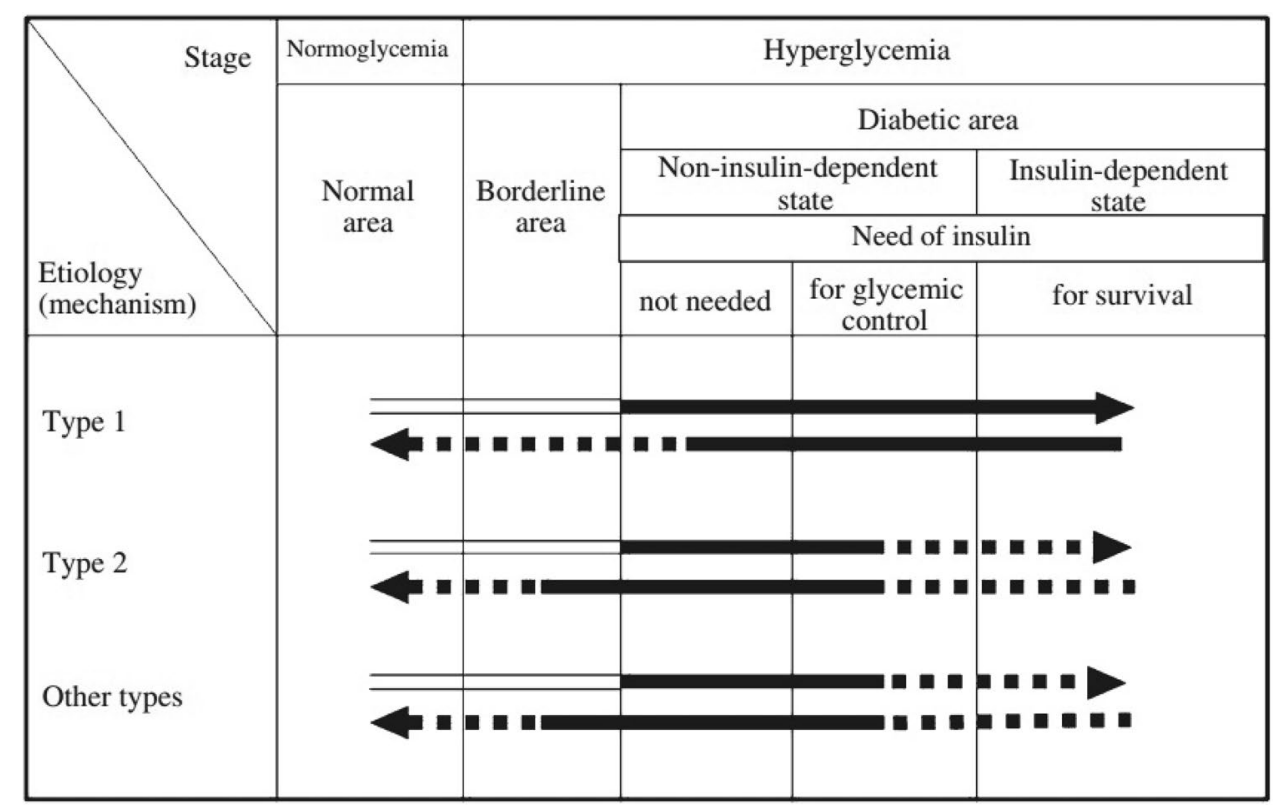

Fig. 3 A schematic diagram of the relationship between the etiology (mechanism) and pathophysiological stages (states) of diabetes mellitus. Arrows pointing right represent the worsening of glucose metabolism disorders (including the onset of diabetes mellitus). Among the arrow lines, indicates the condition classified as "diabetes mellitus". Arrows pointing left represent improvement in the glucose metabolism disorder. The broken lines indicate events of low frequency. For

\section{Q1-6 How is diabetes due to other specific pathophysiological mechanisms or diseases diagnosed?}

- Recent advances in gene analysis techniques have led to a number of single gene abnormalities being identified as causes of diabetes. These are generally divided into: (1) those related to the pancreatic $\beta$-cell function and (2) those related to the mechanisms of insulin action.

- A diabetic condition may occasionally be a part of various diseases, syndromes and pathologies. Some of these were formerly called "secondary diabetes" and include forms of diabetes associated with pancreatic, endocrine and hepatic diseases, drug use, exposure to chemicals, viral infections, and an array of genetic syndromes.

- Gestational diabetes mellitus (GDM) refers to a form of glucose metabolic disorder that is detected or which occurs for the first time during pregnancy and does not reach the criteria of overt diabetes. example, in type 2 diabetes mellitus, infection can lead to ketoacidosis and require temporary insulin treatment for survival. Additionally, once diabetes mellitus has developed, it is treated as diabetes mellitus regardless of the improvement in the glucose metabolism; thus, the arrow lines pointing left are filled in black. In such cases, a broken line is used, because complete normalization of the glucose metabolism is rare

- The diagnosis of these forms of diabetes requires a close review of relevant clinical data, which include: (1) family history and mode of inheritance; (2) age at the onset of diabetes and clinical course; (3) other physical characteristics; and (4) islet autoantibodies.

\section{Q1-7 How do the types of diabetes (their etiology) each relate to their respective pathophysiology (clinical stage)? (Fig. 3)}

- Their etiology (mechanism) and pathophysiological states (stages) represent dimensions distinct from each other and both should be used to describe the condition in each individual patient.

- Whatever the underlying etiology, diabetes may develop through various physical conditions and its pathophysiology may change with the treatment. 
- Pathophysiological states (stages) of diabetes are to be differentiated into the following three stages based on the insufficiency of insulin action: (1) not requiring insulin therapy; (2) requiring insulin therapy for glycemic control; and (3) requiring insulin therapy to prevent ketosis and to support/sustain life.

- Insulin-dependent state refers to the life-threatening status in which patients who do not receive exogenous insulin are prone to ketosis. In contrast, non-insulin dependent state refers to a state in which insulin injection is required not to prevent ketosis or to support/sustain life, but to ameliorate glycemic control. Thus, patients receiving insulin therapy are not always in an insulin-dependent state.

\section{Goals and strategies for diabetes management}

\section{Q2-1 What are the objectives of diabetes management?}

- The objectives of diabetes management are to improve metabolic dysfunctions resulting from hyperglycemia, to prevent the development or progression of diabetic complications and conditions associated with diabetes, and to enable affected individuals to maintain their quality of life (QOL) and life expectancy comparable to those of healthy individuals.

\section{Q2-2 How is a basic diabetes treatment strategy developed for each patient? (Fig. 4)}

- The treatment strategy for diabetes may vary depending on the type, disease condition, age, metabolic abnormality, and status of diabetic complications.

- Insulin therapy is to be given not only to patients who are insulin-dependent, but also to pregnant patients, patients undergoing surgery that involves whole-body management, and patients with severe infection, even if they are not insulin-dependent. In addition, insulin therapy is to be given to those in whom glycemic goals are not achievable with oral hypoglycemic agents (OHAs) or glucagonlike peptide 1 (GLP-1) receptor agonists.

- OHA and/or GLP-1 agonist therapy is to be given to noninsulin-dependent patients in whom favorable glycemic control is not achievable with adequate medical nutrition therapy (MNT) and physical activity/exercise continued for 2-3 months. OHA and/or GLP-1 agonist therapy or insulin therapy may be given to these patients from the outset depending on the severity of the metabolic disorder involved.

- Continued therapy is essential for patients with diabetes to prevent the onset or progression of complications. Team care-based diabetes education for these patients forms the cornerstone of their diabetes treatment.

\section{Q2-3 How is the glycemic goal set for each individual patient? (Fig. 5)}

- Glucose levels in affected individuals should be controlled as close to normal as possible. Achieving and maintaining favorable glycemic control early after initiation of treatment is likely to lead to favorable long-term outcomes in these individuals [1].

\section{Q2-4 How is the onset of chronic diabetic complications prevented or their progression delayed?}

- Diabetes management is aimed not merely at glycemic control [1] but also at ensuring continued smoking cessation and control of blood pressure and lipid levels, thereby preventing chronic diabetic complications or delaying their progression $[2,3]$. 
Fig. 4 Treatment of patients in a non-insulin-dependent state. This provides a guide to the management of patients without acute metabolic disorder [i.e., those who had a casual blood glucose level of $250-300 \mathrm{mg} / \mathrm{dL}$ (13.9-16.7 mmol/L) or less than 250-300 mg/dL with a negative urinary ketone test]. The glycemic goal should be determined individually depending on the disease condition or age of the patient but is generally set at HbA1c $<7.0 \%$. "Diet therapy" and "exercise therapy" are referred to as "medical nutrition therapy (MNT)" and "physical activity/exercise", respectively, elsewhere in this guideline
- Applicable to most cases of type 2 diabetes - Without acute metabolic disorder

- Casual plasma glucose levels approximately $250 \sim 300 \mathrm{mg} / \mathrm{dL}$ or lower

- Negative urinary ketone bodies

The target for glycemic control is established for each patient by the physician-in-charge, taking into account the patient's age and the condition.

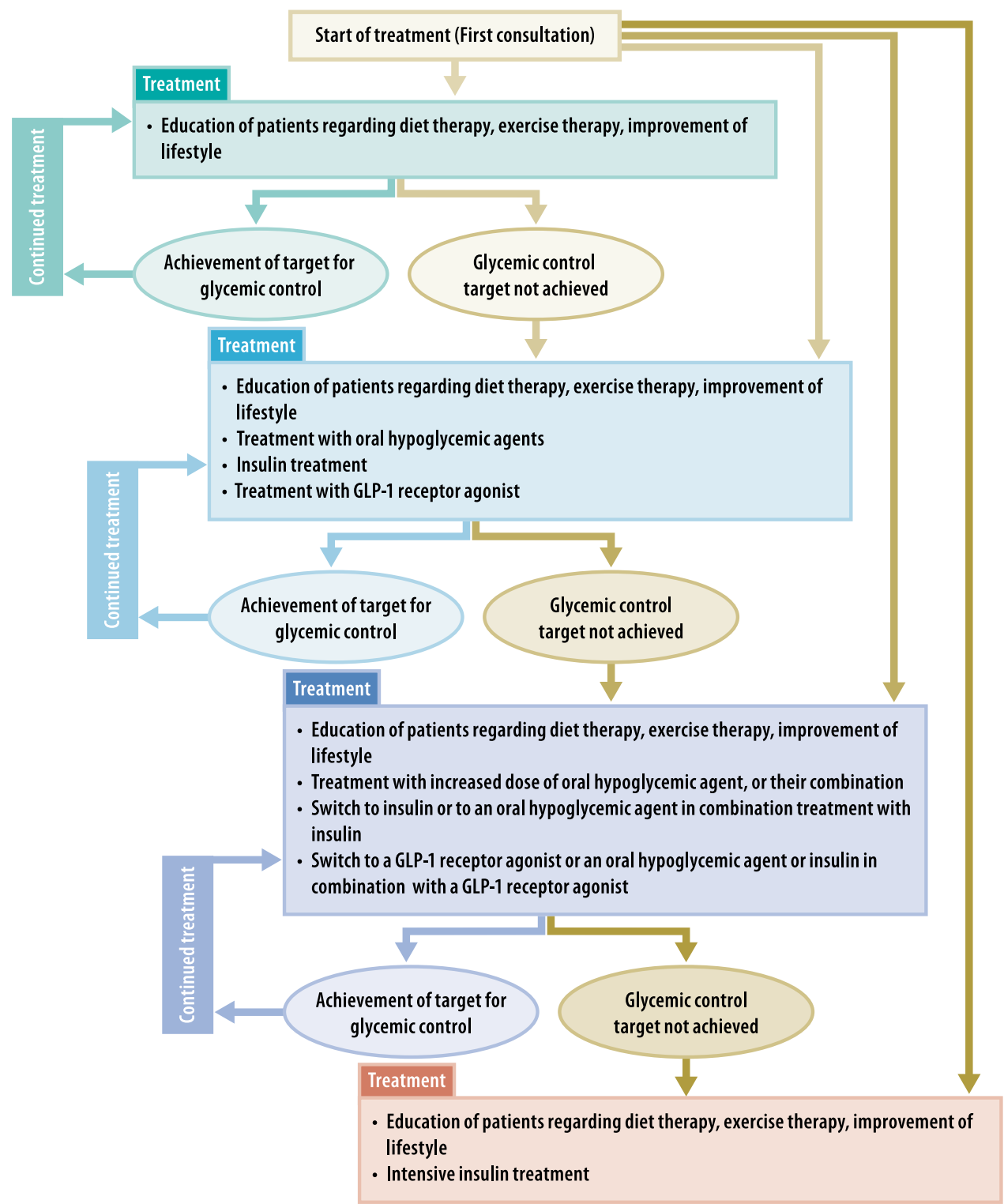


Fig. 5 Glycemic control targets

Control target values $* 4$

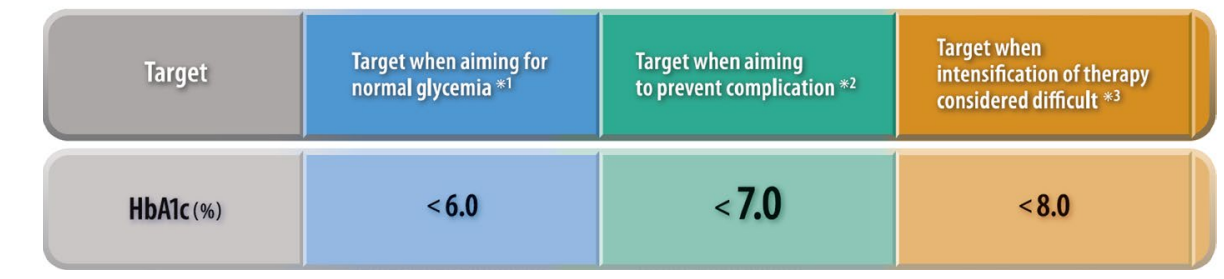

Control targets are established individually, in consideration of age,

duration of disease, organ damage, risk of hypoglycemia, support structures, etc.

*1 When targets can be attained by appropriate MNT or physical activity/exercise, or during pharmacotherapy without the occurrence of side effects such as hypoglycemia.

*2 From the perspective of preventing complication, HbA1c target value is set at $<7 \%$. A fasting blood glucose level $<130 \mathrm{mg} / \mathrm{dL}(7.2 \mathrm{mmol} / \mathrm{L})$ and a 2 -hour postprandial blood glucose level $<180 \mathrm{mg} / \mathrm{dL}(10.0 \mathrm{mmol} / \mathrm{L})$ can be used as an approximate guideline for the corresponding blood glucose levels.

*3 When intensification of treatment is considered difficult due to side effects such as hypoglycemia or for other reasons.

*4 All target values are for adults, not including pregnant women.

\section{Medical nutrition therapy (MNT)}

\section{Q3-1 What is the role of MNT and the optimal nutritional balance in MNT for patients with diabetes?}

- Carbohydrates, proteins and fats should account for $50-60 \%, \leq 20 \%$, and $20-30 \%$, respectively, of the total energy intake in MNT for patients with diabetes.

- The ratios of macronutrients may vary depending on physical activities and the severity of diabetic complications, as well as on the food preferences of each patient with diabetes.

\section{CQ3-2 Is MNT education by registered dieticians effective?}

- MNT education by registered dieticians is effective $[1,2]$ (grade A: 100\% agreement).

\section{Q3-3 What is the ideal body weight (IBW) and how is the total energy intake determined for each patient with diabetes?}

- The goal of MNT for patients with type 2 diabetes is to optimize their total energy intake, thereby helping them maintain a favorable metabolic state.
For each patient with type 2 diabetes, the IBW is to be calculated consistent with a body mass index (BMI) value of 22, and his/her total energy intake is to be calculated by the following equations:

Total energy intake $(\mathrm{kcal} / \mathrm{day})=\mathrm{IBW}(\mathrm{kg}) \times$ physical activity ( $\mathrm{kcal} / \mathrm{kg}$ IBW/day)

IBW $(\mathrm{kg})=(\text { height }[\mathrm{m}])^{2} \times 22$

Physical activity $(\mathrm{kcal} / \mathrm{kg}$ IBW/day $)=$

25-30: light physical activity (e.g., jobs mainly involving desk work).

30-35: moderate physical activity (e.g., jobs mainly involving standing work).

$>35$ : heavy physical activity (e.g., jobs mainly involving heavy physical labor).

- It is less practical to uniformly aim for the IBW in all patients with type 2 diabetes, irrespective of their initial BMI values. Rather, given that the body weight reflects the energy balance, it is advised to aim for a $5 \%$ reduction in body weight in obese individuals with type 2 diabetes; and to aim for the IBW, depending on its possible improvement of metabolic conditions or its feasibility.

\section{Q3-4 How does the dietary carbohydrate intake affect diabetes management?}

- No relationship has been shown between the carbohydrate intake, the risk of diabetes, and glycemic control.

- The consumption of sucrose-containing sweets and juices is not advised, given that they may worsen glycemic control and lead to metabolic syndrome.

- Patients should limit their intake of fruits up to one unit at a time. 
※ In Japan, a common serving size is $80 \mathrm{kcal}$ or a multiple thereof. Thus, $80 \mathrm{kcal}$ is set as 1 unit for discussing amounts of nutrients in MNT.

- The effects of artificial sweeteners on glycemic control have not been fully investigated.

- Instructions on carbohydrate counting are effective in helping patients on insulin therapy achieve optimal glycemic control.

\section{Q3-5 How does the dietary fiber intake affect diabetes management?}

- Given that dietary fiber has been shown to be effective in improving diabetic states, patients with diabetes are encouraged to consume $\geq 20 \mathrm{~g}$ of dietary fiber daily, irrespective of their carbohydrate intake.

- No evidence is available to support food choice based on the glycemic index (GI) in diabetes management.

\section{Q3-6 How does the dietary protein intake affect diabetes management?}

- There is no evidence to demonstrate that an increased protein intake is associated with an increased risk of diabetic nephropathy.

- An intake that accounts for $\geq 20 \%$ of the total energy intake may increase the risk of mortality from any cause including atherosclerosis and the risk of diabetes. No evidence is available to support the long-term safety of the practice.

\section{Q3-7 How does the dietary fat intake affect diabetes management?}

- While no clear relationship has been shown between the total dietary fat intake and the risk of diabetes, an increased saturated fatty acid (SFA) intake has been shown to be associated with the risk of diabetes.

- The dietary fat intake should account for $20-30 \%$ of the total energy intake (SFA, $\leq 7 \%$ ) in patients with diabetes. When it accounts for $>25 \%$, care needs to be taken to modify the fatty acid composition by reducing the SFA intake.

- No evidence is available to support the benefits of n-3 fatty acids in diabetes management.
Q3-8 How does the dietary vitamin and mineral intake affect diabetes management?

- No clear relationship has been shown between the dietary vitamin and mineral intake and diabetes.

\section{Q3-9 How does the dietary salt intake affect diabetes management?}

- Dietary salt restriction has been shown to be useful for reducing the risk of cardiovascular disease in inadequately controlled diabetes.

\section{Q3-10 When is the consumption of alcohol allowable in patients with diabetes?}

- The alcohol intake is to be individualized for each patient with 20-25 g of absolute ethanol equivalent daily as a measure of the upper limit. At present, the differences in how different types of alcoholic beverage impact diabetes management remain unclear; however, attention needs to be paid to carbohydrate-derived energy in low-malt beers. The intake of alcohol may lead to an acute episode of hypoglycemia in patients receiving sulfonylurea (SU) or insulin therapy, and it therefore needs to be closely monitored. Biguanides, which are known to cause lactic acidosis, are contraindicated in individuals whose intake of alcohol is excessive. However, the consumption of alcohol may be allowable, if it is kept reasonable individuals whose diabetes is well controlled and who are capable of self-managing potential problems associated with the intake of alcohol.

\section{Physical activity/exercise}

\section{Q4-1 Is a medical check-up required before implementing physical activity/exercise?}

- Prior to implementing physical activity/exercise in a patient with diabetes, the patient needs to be evaluated for the presence and severity of cardiovascular disease, peripheral/autonomic neuropathy, advanced retinopathy, nephropathy, and orthopedic diseases [1].

- Screening for cardiovascular disease is recommended for asymptomatic patients with multiple risk factors, those with cerebrovascular or peripheral atherosclerotic disease, 
those with electrocardiographic evidence of ischemia, and those undertaking high-intensity exercise [2].

\section{Q4-2 Is exercise effective for patients with type 2 diabetes?}

- Aerobic exercise is associated with improvements in glycemic control [3], insulin resistance, cardiopulmonary function [4], and lipid metabolism [5], as well as reductions in blood pressure (grade A: 100\% agreement).

- Both aerobic and resistance exercise are effective for improving glycemic control, and are even more effective when combined [6] (grade A: 100\% agreement).

\section{CQ4-3 Is exercise effective for patients with type 1 diabetes?}

- While there is no consensus on the effects of exercise on long-term glycemic control [7, 8], exercise is associated with a reduced risk of cardiovascular disease and improved quality of life (QOL) (grade B: 100\% agreement).

\section{Q4-4 What are aerobic and resistance exercise?}

- Aerobic exercise is defined as exercise involving a sufficient supply of oxygen and adenosine triphosphate (ATP) resynthesized through reactions between carbohydrates and lipids as its substrates as energy sources, and continuous rhythmical and repeated movements of the major skeletal muscles lasting for 10 min or longer. Aerobic exercises enhance the cardiopulmonary function. Resistance exercises involve skeletal muscle loading and are performed to enhance the muscular function (muscle strength and endurance).

\section{Q4-5 How should an exercise regimen be implemented in practice?}

- It is generally recommended that exercise involving moderate-intensity aerobic exercise lasting for 20-60 min each time or a total of $\geq 150$ min per week be implemented on a daily basis (preferably), or at least 3-5 times a week. It is also recommended that resistance exercise be implemented 2-3 times a week concurrently with aerobic exercise [1].
- It is advisable to increase the intensity and amount of exercise in a stepwise fashion and to include warm-ups and cool-downs before and after exercise in daily life. It is also advisable to examine both feet closely and to use properly fitting cushioned shoes.

- Patients receiving insulin or glucose-lowering agents (SUs in particular) may experience episodes of hypoglycemia during exercise, on the day of exercise, or on the day after exercise. It is therefore recommended that patients receiving insulin adjust the duration, type and amount of exercise being performed and the doses of drugs being used (as a rule, a dose reduction of ultra-fast-acting insulin before exercise) and to eat as required before and during exercise through the self-monitoring of blood glucose (SMBG). It is especially recommended that patients receiving insulin consume one to two units of easily absorbed carbohydrates before exercise if their pre-exercise glucose level is below $100 \mathrm{mg} / \mathrm{dL}$ (5.6 mmol/L) [1].

- Patients who are in good physical condition may not need to discontinue exercise simply due to hyperglycemia; however, patients with type 1 diabetes and urine ketone bodies should refrain from exercise [9].

\section{Treatment with glucose-lowering agents (excluding insulin)}

\section{Q5-1 What are the indications for glucose-lowering agents?}

- Glucose-lowering agents are indicated for patients with non-insulin-dependent stages of diabetes who fail to achieve favorable glycemic control with adequate MNT and/or physical activity/exercise of 2-3 months in duration [1-3]. However, glucose-lowering agents, including insulin, are indicated, along with MNT and/ or physical activity/exercise, for patients in non-insulin-dependent stages who require the elimination of glucotoxicity.

- The absolute indications for insulin therapy include type 1 diabetes, pregnancy complicated by diabetes not amenable to control by MNT alone, diabetic coma, severe infection, surgery requiring whole-body management In these cases, glucose-lowering agents are not indicated and insulin therapy should be initiated immediately.

\section{Q5-2 How are glucose-lowering agents chosen for diabetes treatment?}

- The choice of glucose-lowering agents should be individualized for each patient according to the disease con- 
dition, with attention also given to their pharmacological and safety profiles. With informed consent obtained from the patient, the drug(s) should be initiated at a low dose and gradually titrated upwards as required depending on the glycemic control of the patient at that time.

\section{Q5-3 What are the characteristics of sulfonylureas (SUs)?}

- Sulfonylureas (SUs) potently lower blood glucose level through their ability to promote the secretion of insulin from pancreatic $\beta$ cells and current evidence demonstrates their usefulness in reducing microangiopathy [3]. SUs have been shown to readily exert their effects in patients with preserved insulin capacity; however, they have often been shown to be associated with the side effect of hypoglycemia. SUs are also associated with weight gain in patients who are less adherent to MNT and/or physical activity/exercise [8].

\section{Q5-4 What are the characteristics of biguanides?}

- Biguanides are currently used as first-line glucose-lowering agents in Western countries. Biguanides exert their effect by inhibiting hepatic glucose production as well as by improving peripheral insulin sensitivity. Current evidence demonstrates their usefulness in reducing macroangiopathy in patients with type 2 diabetes [4-6,9]. Although they are rarely associated with lactic acidosis, caution needs to be taken to determine whether the patient can be safely treated with biguanides.

\section{Q5-5 What are the characteristics of a-glucosidase inhibitors?}

- $\alpha$-Glucosidase inhibitors, which inhibit intestinal glycolysis and delay intestinal glucose absorption, suppress postprandial hyperglycemia and hyperinsulinemia and should be taken immediately before meals; they are also often associated with flatus and diarrhea. Hypoglycemia in patients treated with these agents can be effectively improved with the ingestion of only glucose.

\section{Q5-6 What are the characteristics of thiazolidinediones (TZDs)?}

- Thiazolidinediones (TZDs) improve glycemic control by promoting peripheral insulin sensitivity and inhibiting hepatic glucose release; they are also often associated with weight gain due to their ability to promote fluid retention and adipocyte differentiation. Patients receiving TZDs require monitoring for edema, anemia and fracture associated with the use of TZDs [10-14].

\section{Q5-7 What are the characteristics of glinides?}

- Glinides correct postprandial hyperglycemia by immediately promoting insulin secretion, with their action diminishing in such a short time that they are less associated with the risk of hypoglycemia.

\section{Q5-8 What are the characteristics of DPP-4 inhibitors?}

- DPP-4 inhibitors glucose-dependently promote postprandial insulin secretion while at the same time inhibiting glucagon secretion, thus improving both fasting and postprandial hyperglycemia. While the risk of hypoglycemia with DPP-4 inhibitor monotherapy is small, combination therapy with an SU or insulin often increases the risk of hypoglycemia, suggesting the rationale for reducing the dose of either partnering agent [15-19].

- DPP-4 inhibitors were previously thought to be associated with the risk of acute pancreatitis, pancreatic cancer or infections; however, current evidence appears to argue against this [20]. They are not associated with an increased risk of macroangiopathy [21-23]. Thus, at present, DPP-4 inhibitors appear to have a favorable safety profile.

\section{Q5-9 What are the characteristics of GLP-1 receptor agonists?}

- GLP-1 receptor agonists, which are available as injectable agents, promote postprandial insulin secretion in a glucose-dependent manner while at the same time inhibiting glucagon secretion; thus they improve both fasting and postprandial hyperglycemia and are less associated with a risk of hypoglycemia. While these agents have also been shown to exert their glucose-lowering effect 
in combination with an SU or insulin, this combination therapy has been shown to be associated with an increased risk of hypoglycemia, suggesting the rationale for reducing the dose of either partnering agent [24, 25].

- GLP-1 receptor agonists are associated with gastrointestinal symptoms. Thus, to alleviate the onset of such symptoms, GLP-1 receptor agonists need to be initiated at a low dose and titrated upwards as required. Current evidence suggests that these agents are not associated with a risk of acute pancreatitis [26]; their cardiovascular safety has also been demonstrated [27].

\section{Q5-10 What are the characteristics of SGLT2 inhibitors?}

- SGLT2 inhibitors inhibit glucose reabsorption in the proximal renal tubule and promote urinary glucose excretion, thus exerting their glucose-lowering effect; they not only improve glycemic control independently of insulin-mediated mechanisms but also associated with body weight reduction.

- Among the SGLT2 inhibitors, empagliflozin has been shown to significantly delay the onset of cardiovascular events in patients at high-risk for these events [7].

- SGLT2 inhibitors are associated with an increased frequency of urinary tract infections and genital infections as adverse effects [7, 28, 29]. Other adverse effects include dehydration accompanied by symptoms such as thirst, polyuria, pollakiuria, or hypotension, dehydrationassociated thromboembolism including cerebral infarction, events associated with increased ketone bodies, and an increased incidence of rash. Their clinical implications require currently further examination.

\section{Q5-11 Is combination therapy with glucose-lowering agents effective?}

- In patients failing to achieve their glycemic target while on monotherapy with a first-line agent, consideration may be given to increasing the dose of the first-line agent, switching to a more potent glucose-lowering agent, or combining the first-line agent with another glucoselowering agent with a different mechanism of action. No clear synergistic effect has been demonstrated between agents used in combination, and no guidelines have been established for combination therapy with glucose-lowering agents.

- In patients with inadequate glycemic control despite monotherapy with an SU or metformin, combination therapy with another glucose-lowering agent with a different mechanism of action is usually considered; combination therapy with such agents has shown to be effective for lowering glucose levels [30, 31-36]. Combination therapy with three or more agents (other than combinations of an SU and a glinide or a DPP-4 inhibitor and a GLP-1 receptor agonist) has been shown to be effective for lowering glucose levels [37-41].

\section{Q5-12 How should patients with inadequate glycemic control despite treatment with glucose-lowering agents be managed?}

- In patients with inadequate glycemic control despite combination therapy with glucose-lowering agents, consideration needs to be given to reassessing MNT and/ or physical activity/exercise as well as to adding basal insulin therapy or switching to intensive insulin therapy.

\section{Insulin therapy}

\section{Q6-1 What types of insulin formulation are available?}

- The currently available insulin formulations are classified based on their onset/duration of action into rapid-acting insulin, regular insulin, intermediate-acting (neutral protamine Hagedorn, NPH) insulin, long-acting insulin, premixed regular/intermediate-acting, premixed rapidacting/intermediate-acting (or biphasic) insulin, and rapid-acting and long-acting insulin combination formulations.

- Intermediate- or long-acting insulin formulations are used to supplement basal insulin secretion, while regular or rapid-acting insulin formulations are used to supplement bolus insulin secretion.

\section{Q6-2 What are the indications for insulin therapy?}

- Absolute indications for insulin therapy include insulin-dependent states, including type 1 diabetes, hyperglycemic coma (diabetic ketoacidosis, hyperglycemic hyperosmolar syndrome, lactic acidosis), and pregnancy complicated by diabetes that is not adequately controlled by MNT alone. Insulin therapy is also recommended for serious infections and surgery requiring systemic management. 
- Insulin therapy is also implemented in patients with type 2 diabetes having inadequate glycemic control despite MNT, increased physical activity/exercise and therapy with non-insulin glucose-lowering agents or when hyperglycemia-associated glucose toxicity must be eliminated.

\section{Q6-3 What are the adverse reactions that occur in association with insulin therapy?}

- Insulin therapy may be associated with hypoglycemia as well as a transient worsening of retinopathy or neuropathy in some patients $[1,2]$. Patients receiving insulin therapy need to be monitored for long-term risks associated with insulin therapy, such as weight gain [3].

\section{Q6-4 What approaches are available for insulin therapy in type 1 diabetes?}

- Multiple insulin injection therapy (3-4 injections/day) or continuous subcutaneous insulin infusion (CSII) are available to optimize glycemic control in type 1 diabetes [4].

\section{CQ6-5 Is intensive insulin therapy effective in suppressing microangiopathy in type 1 diabetes?}

- Intensive insulin therapy, which combines multiple insulin injections or CSII and self-monitoring of blood glucose (SMBG) has been shown to be effective in preventing the onset of microangiopathy (retinopathy, nephropathy and neuropathy) and in suppressing their progression $[4,5]$ (grade A: $100 \%$ agreement).

\section{CQ6-6 Is intensive insulin therapy effective} in suppressing macroangiopathy in type 1 diabetes?

- Intensive insulin therapy that combines multiple insulin injection therapy and SMBG has been shown to also be effective in suppressing the progression of macroangiopathy (coronary artery disease, cerebrovascular disease, and peripheral artery disease) $[6,7]$ (grade A: $100 \%$ agreement).

\section{Q6-7 What are the indications/approaches for insulin therapy in type 2 diabetes?}

- Insulin therapy is to be implemented in patients with type 2 diabetes having inadequate glycemic control despite MNT, increased physical activity/exercise and treatment with non-insulin glucose-lowering agents [3, 8-10].

- While once-daily injection of long-acting insulin or twice-daily premixed insulin (morning and evening) may be sufficient to provide favorable glycemic control in patients with mild diabetes, intensive insulin therapy with multiple insulin injection is to be implemented in those with moderate to severe diabetes $[8,11,12]$.

- Combination therapy with insulin and oral glucose-lowering agents (SUs [13, 14], fast-acting insulin secretagogues [glinides] [15-17]), biguanides [18-21], $\alpha$-glucosidase inhibitors [22, 23], insulin sensitizers [24-27], and, DPP-4 inhibitors [28]) or GLP-1 receptor agonists [29] are shown to improve glycemic control and reduce the insulin dose being used in patients with type 2 diabetes.

\section{CQ6-8 Is intensive insulin therapy effective in suppressing microangiopathy in type 2 diabetes?}

- Strict glycemic control with intensive insulin therapy has been shown to be effective in preventing the onset of microangiopathy (retinopathy, nephropathy, and neuropathy) as well as in suppressing the progression of microangiopathy $[8,9]$ (grade A: 100\% agreement).

\section{Q6-9 Is intensive insulin therapy effective in suppressing macroangiopathy in type 2 diabetes?}

- Intensive insulin therapy has been shown to be effective in preventing the onset of macroangiopathy in type 2 diabetes $[9,30,31]$. 
7 Diabetes self-management education and support for the self-management of diabetes

\section{CQ7-1 Are organized support and education for the self-management of diabetes and support useful for the management of diabetes?}

- Organized education and support for the self-management of diabetes and have been shown to be useful for diabetes management $[1,2]$ (grade A: $100 \%$ agreement).

\section{CQ7-2 Is the group and individualized education useful for the diabetes management?}

- Both group and individualized education has been shown to be useful for diabetes management [3,4] (grade A: $85 \%$ agreement).

\section{CQ7-3 Is the self-monitoring of blood glucose} (SMBG) useful for diabetes management?

- SMBG has been shown to be useful for patients with type 1 diabetes and for patients with type 2 diabetes receiving insulin therapy $[5,6]$ (grade A: 95\% agreement).

\section{Q7-4 What are the psychological issues in diabetes management and treatment?}

- Diabetes is often associated with depressive symptoms and anxiety disorders specific to the disease, leading to deficient self-care, worsening of glycemic control, an increased risk of diabetic complications, and an impaired QOL, thus adversely affecting the prognosis of affected patients. Intervention that addresses both depressive symptoms and diabetes-related mental distress and anxiety is required to improve the self-care abilities and glycemic control of affected patients.
CQ7-5 Are psychological/behavioral approaches effective in diabetes management?

- Psychological/behavioral approaches have been shown to be effective in diabetes management $[7,8]$ (grade A: 95\% agreement).

\section{Q7-6 Is depression screening/treatment important in diabetes management?}

- After at-risk patients with diabetes are screened for depression, systematically coordinated care for both diabetes and depression is essential $[9,10]$.

\section{Q7-7 How are the available guidelines and practice manuals to be used in practice?}

- Practice manuals represent guides for clinicians as to how to translate the treatment policies defined in the guidelines into daily clinical practice as they are based on systematic reviews of the available scientific evidence. Healthcare teams and patients are encouraged to share relevant information and promote decisions that would honor the needs and preferences of individual patients.

\section{Diabetic retinopathy}

CQ8-1 Is a routine ophthalmologic check-up useful for preventing the onset/progression of diabetic retinopathy?

- A routine ophthalmologic check-up has been shown to be useful for preventing the onset/progression of diabetic retinopathy [1-4] (grade A: 100\% agreement).

\section{CQ8-2 Is glycemic control useful} for the management of diabetic retinopathy?

- Glycemic control has been shown to be useful in suppressing the onset/progression of diabetic retinopathy in patients with type 1 and type 2 diabetes [5-7] (grade A: $100 \%$ agreement). 


\section{CQ8-3 Is blood pressure control useful for the management of diabetic retinopathy?}

- Blood pressure control has been shown to be useful for suppressing the onset/progression of diabetic retinopathy in patients with type 2 diabetes $[8,9]$ (grade A: $100 \%$ agreement)

\section{CQ8-4 Is lipid control useful for the management of diabetic retinopathy?}

- Fenofibrates have been shown to have the potential to suppress the progression of diabetic retinopathy in dyslipidemia complicated by type 2 diabetes $[7,10]$ (grade B: $100 \%$ agreement).

\section{Q8-5 Are antiplatelet agents useful for preventing the onset/progression of retinopathy?}

- There is no clinical evidence to suggest the usefulness of antiplatelet agents in suppressing the onset/progression of diabetic retinopathy.

\section{CQ8-6 Is ophthalmologic treatment useful for preventing the progression of retinopathy?}

- Ophthalmologic treatment such as retinal photocoagulation has been shown to be useful for suppressing the progression of retinopathy $[11,12]$ (grade A: $100 \%$ agreement).

\section{Q8-7 Is pregnancy with pre-existing diabetes a risk factor for the onset/progression of diabetic retinopathy?}

- Pregnancy with pre-existing diabetes has been shown to promote the onset/progression of diabetic retinopathy [13-15].
Q8-8 Is diabetic retinopathy a risk factor for the onset of other diabetes-associated complications?

- Diabetic retinopathy is a risk factor for diabetic nephropathy and macroangiopathy [16-20].

\section{Diabetic nephropathy}

\section{CQ9-1 Is the measurement of urinary albumin useful} for the early diagnosis of diabetic nephropathy?

- The measurement of urinary albumin has been shown to be useful in the early diagnosis of diabetic nephropathy [1] (grade A: $100 \%$ agreement).

\section{Q9-2 What parameters are used to assess the renal function?}

- The renal function is to be evaluated as the estimated glomerular filtration rate (eGFR) from the serum creatinine (Scr) concentration, as determined by an enzymatic method [17].

- Insulin clearance (Ic) or creatinine clearance (Ccr) allows the renal function to be more accurately assessed than the eGFR.

- Estimated glomerular filtration rate (eGFR).

1. The eGFR is easily assessed as an index of the renal function, rather than Ccr or insulin clearance (Cin). The eGFR is calculated by the following equation for Japanese adults based on the Scr concentration [17]:

$$
\begin{aligned}
& \operatorname{eGFR}\left(\mathrm{mL} / \mathrm{min} / 1.73 \mathrm{~m}^{2}\right)= 194 \times \mathrm{Scr}(\mathrm{mg} / \mathrm{dL})-1.094 \\
& \times \operatorname{Age}^{-0.287}(\times 0.789, \text { if female }) .
\end{aligned}
$$

The accuracy rate of this equation (within $30 \%$ of the measured GFR) is $75 \%$. The eGRF may be overestimated in subjects with reduced muscle mass.

2. Alternatively, the eGFR can be calculated by the following equation based on the serum cystatin $\mathrm{C}$ (Cys-C) concentration [19]:

$$
\begin{aligned}
\text { eGFRcys }-\mathrm{c}\left(\mathrm{mL} / \mathrm{min} / 1.73 \mathrm{~m}^{2}\right)= & 104 \times \text { Cys }-\mathrm{C}-1.019 \\
& \times 0.996^{\mathrm{Age}}(\times 0.996, \text { if female })-8 .
\end{aligned}
$$

The serum Cys-C concentration is influenced by muscle mass or diet (or nutritional conditions). 


\section{CQ9-3 Is glycemic control effective for the management of diabetic nephropathy?}

- Glycemic control has been shown to be effective for suppressing the progression of nephropathy in patients with early stage diabetic nephropathy [2, 3] (grade A: $90 \%$ agreement).

- Glycemic control has been shown to have the potential to suppress the progression of nephropathy in patients with overt diabetic nephropathy [4] (grade B: 90\% agreement).

\section{CQ9-4 Is blood pressure control effective for the management of diabetic nephropathy?}

- Blood pressure control has been shown to be effective for the management of diabetic nephropathy in all stages [5-7] (grade A: 95\% agreement).

\section{CQ9-5 Is lipid control effective for the management of diabetic nephropathy?}

- Lipid control has been shown to be effective for suppressing the progression of diabetic nephropathy in patients without renal impairment [8,9] (grade B: 95\% agreement).

CQ9-6 Are angiotensin-converting enzyme (ACE) inhibitors and angiotensin II receptor antagonists (ARBs) recommended as first-line medications for blood pressure control in patients with diabetic nephropathy?

- Angiotensin-converting enzyme (ACE) inhibitors and angiotensin II receptor antagonists (ARB) are recommended as first-line medications for blood pressure control in patients with diabetic nephropathy $[10,11]$ (grade A: $100 \%$ agreement).

\section{CQ9-7 Is dietary salt restriction recommended for the management of diabetic nephropathy?}

- Dietary salt restriction is recommended for the management of diabetic nephropathy $[12,13]$ (grade A: 95\% agreement).
Q9-8 Is dietary protein restriction effective for the management of diabetic nephropathy?

- Dietary protein restriction may potentially be effective for the management of diabetic nephropathy $[14,15]$.

\section{Q9-9 Is the treatment of anemia effective for suppressing the progression of diabetic nephropathy?}

- It remains unclear if the treatment of anemia may have a role in suppressing the progression of diabetic nephropathy [16].

\section{Q9-10 Is diabetic nephropathy a risk factor for other} complications in diabetic patients?

- Diabetic nephropathy frequently occurs concomitantly with cardiovascular disease.

- Patients with diabetic nephropathy show a high rate of cardiovascular disease-related mortality.

- A decreased GFR and the occurrence of albuminuria are independent risk factors for cardiovascular disease [18].

\section{Diabetic neuropathy}

\section{Q10-1 How is diabetic neuropathy diagnosed?} (Table 4)

- Diabetic neuropathy represents one of the most common complications in patients with diabetes. It is therefore preferable that patients with diabetes undergoing physical examinations be examined for the presence or absence of diabetic neuropathy; if present, its clinical stage determined.

- In diagnosing diabetic neuropathy, patients are to be not only interviewed about neurological symptoms, but also to be examined for sensations such as pain sensation (with a toothpick/bamboo skewer), vibration sensation (with a C128 tuning fork), pressure sensation (with a monofilament) as well as for Achilles' tendon reflex; the assessment can be as comprehensive as possible. Other findings, such as dry feet, cracked feet, foot calluses or ulcers, may suggest the presence of neuropathy and prove helpful in establishing the diagnosis. 
Table 4 The diagnostic criteria for distal symmetric polyneuropathy proposed by the Diabetic Neuropathy Study Group, Japan (the original version was published in 2004; the revised version was published in 2005)

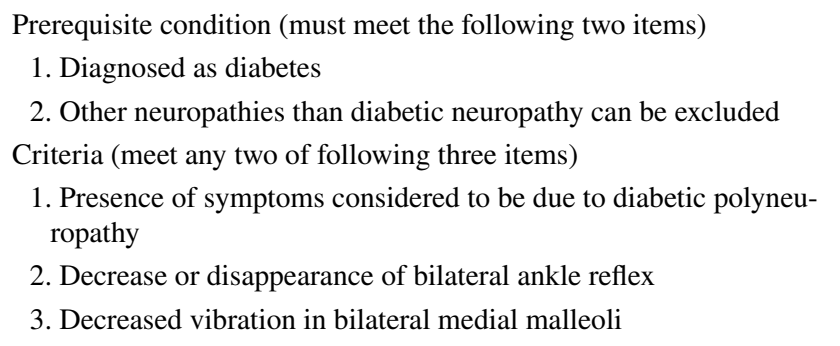

Diabetic neuropathy has no specific symptoms or assessments and no global consensus has been reached on its diagnostic criteria. Thus, while a comprehensive assessment is required to establish its diagnosis based on neurological symptoms and laboratory test results, the validity of the criteria proposed by the Japanese Study Group of Diabetic Nephropathy $[12,13]$ is thought to be high enough for routine clinical use

- Heart rate variability (HRV) testing is a convenient and useful test to assess the autonomic nerve function.

- Nerve conduction examinations are essential for the definitive diagnosis of diabetic neuropathy and are useful in the diagnosis of asymptomatic neuropathy.

\section{Q10-2 How is diabetic neuropathy classified?}

- Diabetic neuropathy is divided into distal symmetric polyneuropathy and focal mononeuropathy $[1,2]$.

\section{Q10-3 What are the risk factors for the onset/ progression of diabetic neuropathy?}

- The risk factors for the onset/progression of diabetic neuropathy include: (1) poor glycemic control, (2) duration of diabetes, (3) hypertension, (4) dyslipidemia, (5) smoking, and (6) drinking [3]. Among these, poor glycemic control is the most prominent risk factor; indeed, the incidence of neuropathy in patients with poor glycemic control has been shown to be high.
CQ10-4 Is glycemic control effective for the management of diabetic neuropathy?

- Strict glycemic control has been shown to suppress the onset/progression of diabetic neuropathy [4, 5] (grade A: 95\% agreement).

\section{Q10-5 How is pharmacotherapy to be implemented in patients with neurosensory damage?}

- Neurosensory damage often resolves with improved glycemic control and lifestyle modification in patients with mild painful neuropathy. Non-steroidal anti-inflammatory drugs (NSAIDs) have only been shown to be effective in mild cases.

- Tricyclic antidepressants [6], pregabalin [7, 8], and duloxetine $[9,10]$ are recommended as first-line medications for patients with moderate to severe painful neuropathy.

- Epalrestat has been shown to suppress the progression of diabetic neuropathy in some patients.

\section{Q10-6 How is autonomic nerve damage treated?}

- Neurosensory damage often improves with improved glycemic control and lifestyle modification in patients with mild autonomic neuropathy. However, symptom-specific pharmacotherapy is required for patients whose activities of daily living (ADL) are impaired in association with advanced neuropathy.

\section{Q10-7 How is mononeuropathy treated ?}

- Mononeuropathy has been shown to often resolve spontaneously, independent of glycemic control.

\section{Q10-8 Is diabetic neuropathy a risk factor for other complications in diabetic patients?}

- Diabetic neuropathy has been shown to be a risk factor for diabetic retinopathy and nephropathy [11]. 


\section{Diabetic foot}

\section{Q11-1 What is diabetic foot?}

- Diabetic foot is globally defined as "infections, ulcers and destructive lesions occurring on the lower limb tissue of patients with diabetes in association with ongoing neuropathy and peripheral artery disease".

- Diabetic foot occurs in response to external factors in the presence of hypoesthesia due to neuropathy, foot deformities, dry or keratinized skin, and decreased blood flow due to peripheral artery disease. When diabetic foot is complicated by infection, it is likely to become severe, leading not only to lower limb amputation, but also to a worse prognosis $[1,2]$.

\section{CQ11-2 Is a routine foot examination effective for the prevention of diabetic foot?}

- While there is a paucity of evidence to support the effectiveness of routine foot examinations in the prevention of diabetic foot, the incidence of lower limb amputations has been observed to decrease following the introduction of foot care, including foot examinations, in clinical practice [4]. Foot examinations are essential for the early detection of diabetic foot and the implementation of foot care and are thus thought to be effective for the prevention of diabetic foot (grade A: $85 \%$ agreement).

\section{CQ11-3 Is foot care education effective for the prevention of diabetic foot?}

- Foot care education is thought to promote the acquisition of relevant knowledge and improve self-care activities and is thus thought likely to be effective for achieving the longterm prevention of diabetic foot $[1,5]$ (grade A: $90 \%$ agreement).

\section{CQ11-4 Is glycemic control effective for preventing diabetic foot or lower limb amputations?}

- To date, very few studies have investigated the effects of intervention with regard to glycemic control on diabetic foot or amputations [6]; however, glycemic control is recommended for the prevention of neuropathy and macroan- giopathy, which are risk factors for diabetic foot (grade B by consensus: $100 \%$ agreement).

\section{CQ11-5 Is foot care effective for the prevention of foot ulcers or limb salvage in high-risk patients?}

- While very few studies have shown direct evidence to support the effectiveness of foot care in the prevention of foot ulcers or lower limb amputations in high-risk patients, multidisciplinary collaboration on foot care has been shown to reduce the incidence of major amputations [7] (grade A: $100 \%$ agreement).

\section{Q11-6 How are foot ulcers treated?}

- The treatment of diabetic foot in patients with diabetes entails a wide array of interventions, which include control of their general condition, local procedures (i.e, debridement), the treatment of infectious disease, revascularization for severe lower limb ischemia, the use of non-weight bearing/off-loading devices and specially prepared shoes, walking rehabilitation, nutritional education, and care support, in which multidisciplinary teambased care involving diverse specialists and practitioners remains the cornerstone [1].

- Infections, abscesses or necrotizing fasciitis associated with the presence of gas in the deep tissues are indications for emergency surgery. While no established criteria are available with regard to for indications for amputation, the blood flow of the prospective amputation site must be evaluated prior to amputation $[9,10]$.

\section{CQ11-7 Is team-based care effective in preventing diabetic foot and treating foot ulcers?}

- Multidisciplinary team-based care is reported to improve the outcomes of foot ulcer treatment [8]. While there is no direct evidence to show that multidisciplinary teambased care prevents diabetic foot ulcers, the incidence of foot amputations has decreased over time since the establishment of multidisciplinary team-based care, suggesting that multidisciplinary team-based care is effective in preventing foot lesions [11] (grade A: 100\% agreement). 
CQ11-8 Is foot ulcer treatment effective in maintaining the quality of life (QOL) of affected patients?

- Foot ulcer treatment has been shown to be effective in maintaining the QOL of affected patients [12,13] (grade A: $100 \%$ agreement).

\section{Q11-9 Is diabetic foot a risk factor for other complications in patients with diabetes?}

- Diabetic foot is significantly associated with the onset of cardiovascular disease, higher overall mortality and the onset of depression, suggesting that diabetic foot represents a risk factor for mortality, cardiovascular disease and depression $[3,14]$.

\section{Diabetic macroangiopathy}

\section{Q12-1 When and how is risk management} to be initiated for the prevention of diabetic macroangiopathy?

- It is recommended that the established risk factors for diabetic macroangiopathy [i.e., impaired glucose tolerance (IGT), hypertension, dyslipidemia, obesity, and chronic kidney disease (CKD)], be detected and managed at an early stage [1].

\section{Q12-2 In which diabetic patient is risk management likely to be beneficial in preventing diabetic macroangiopathy?}

- All patients with diabetes may be deemed candidates for risk management. However, tight pharmacological blood pressure and glucose control may be adversely associated with an increased risk of events in older patients or those with advanced vascular complications [2].
CQ12-3 Are the modification of lifestyle habits and the correction of obesity effective in preventing diabetic macroangiopathy?

- Conditions, such as IGT, hypertension, dyslipidemia, obesity, and CKD, and lifestyle habits, such as physical inactivity, an excessive salt intake, and smoking, all represent risk factors for cardiovascular events. The modification of lifestyle habits and the correction of obesity are recommended, given that they are shown to be associated with the amelioration of these risk factors [3] (grade A: 95\% agreement).

\section{CQ12-4 Is glycemic control effective against diabetic macroangiopathy?}

- Tight glycemic control, initiated early after the onset of diabetes, has been shown to be effective in suppressing the risk of diabetic macroangiopathy [4] (grade A: 100\% agreement).

CQ12-5 Is blood pressure control effective in preventing diabetic macroangiopathy?

- Tight blood pressure control has been shown to be effective in suppressing the risk of diabetic macroangiopathy [5] (grade A: 100\% agreement).

\section{CQ12-6 Is lipid control effective in preventing diabetic macroangiopathy?}

- Lipid control has been shown to be effective in the primary and secondary prevention of diabetic macroangiopathy [6, 7] (grade A: $100 \%$ agreement).

\section{CQ12-7 Are antiplatelet agents effective in preventing diabetic macroangiopathy?}

- The use of antiplatelet agents has been shown to be effective in the secondary prevention of diabetic macroangiopathy [8] (grade A: 100\% agreement). 
- The use of antiplatelet agents is not recommended for the primary prevention of diabetic macroangiopathy in patients with diabetes [9] (grade A: 90\% agreement).

\section{Q12-8 Is diabetic macroangiopathy a risk factor for other complications in diabetic patients?}

- Hyperglycemia represents a common risk factor for diabetic retinopathy, nephropathy, neuropathy, and macroangiopathy, thus suggesting a relationship between these conditions. However, at present, there is no clear evidence to demonstrate any direct relationship.

\section{Diabetes and periodontitis}

\section{Q13-1 What is periodontal disease?}

- Periodontal disease is an inflammatory disease involving plaque bacteria and is broadly classified into gingivitis, in which inflammation is confined to the gingiva, and periodontitis, which involves a loss of supporting tissue.

- Periodontal disease is a disease of the oral cavity that is reported to affect approximately $80 \%$ of the Japanese individuals of middle age or older and is the foremost cause of dental extraction.

- The treatment of periodontal disease entails not only establishing plaque control in affected patients but also improving inflammation through plaque and calculus removal from periodontal pockets and ensuring routine post-removal periodontal maintenance care aimed at preventing a relapse of the disease.

\section{Q13-2 Does diabetes influence the onset/ progression of periodontal disease?}

- Periodontal disease has been shown to occur more frequently among patients with type 1 diabetes in comparison to young healthy individuals [1].

- The risk of the onset of periodontal disease and the progression of alveolar bone resorption is significantly increased in patients with type 2 diabetes and an $\mathrm{HbA} 1 \mathrm{c}$ value of $\geq 6.5 \%[2]$.
CQ13-3 Is diabetes treatment effective in improving periodontal disease?

- Diabetes treatment may lead to the improvement of periodontal tissue inflammation [4] (grade B: 100\% agreement).

\section{Q13-4 Does periodontal disease affect glycemic control?}

- Periodontal disease as an inflammatory disease has been epidemiologically shown to adversely affect glycemic control [5].

- As periodontal disease becomes more severe, it becomes more difficult to achieve glycemic control in affected patients [3].

\section{CQ13-5 Is treating periodontal disease effective in improving glycemic control?}

- The treatment of periodontal disease has been shown to lead to improvement in the glycemic status of some patients with type 2 diabetes [6] (grade B: 95\% agreement).

\section{Diabetes complicated by obesity (including metabolic syndrome)}

\section{Q14-1 What are the causes of obesity?}

- Obesity is classified into secondary obesity (i.e., obesity with clear underlying causes), and primary obesity (i.e., obesity with no clear causes but which is associated with lifestyle habits such as physical inactivity) [1].

- While primary obesity is most frequent of all forms of obesity, secondary obesity includes endocrinologically induced obesity, inherited obesity, hypothalamic obesity and drug-induced obesity [1].

\section{Q14-2 How is obesity diagnosed?}

- In Japan, obesity is defined by a body mass index (BMI) of $\geq 25 \mathrm{~kg} / \mathrm{m}^{2}$ or higher according to the Japan Society for the Study of Obesity; however, obesity should not to 
be handled as a disease in patients without health problems [1].

- Obesity should be handled as a disease in patients with obesity-induced or obesity-associated health problems or in patients who are likely to have obesity-associated health problems and for whom weight loss is medically indicated [1].

- Obesity as a disease includes (1) obesity-induced or obesity-associated conditions requiring weight reduction for health problems (that are likely to be improved or prevented with a certain level of weight loss); and (2) visceral fat-associated obesity (visceral fat area $\geq 100 \mathrm{~cm}^{2}$ at the umbilical level measured by CT in patients who are currently free of, but who are likely to develop health problems such as diabetes (defined as high-risk obesity requiring intervention with lifestyle modification) [1].

\section{Q14-3 How is obesity-associated diabetes to be managed?}

- Secondary obesity is to be carefully ruled out in patients with type 2 diabetes and obesity, and those who are thought to be likely to have primary obesity are to be interviewed about their living environmental and psychological factors. Attention is to be paid to the discontinuation or modification of any lifestyle habits that cause obesity [2]. This is to entail, first, instructing patients on lifestyle modification including MNT and/or physical activity/exercise, stress management and a regular lifestyle to lose weight [2]. Pharmacotherapy is to be considered for patients whose glycemic control is inadequate despite maintaining lifestyle modifications over a certain period [2].

- Left untreated, obesity often becomes more severe in diabetic patients and obese patients receiving therapy for hyperglycemia alone [3]. Attention needs to be focused on ensuring that these patients proactively modify their lifestyles to achieve favorable glycemic control without weight gain [3].

\section{Q14-4 Is behavioral therapy effective in reducing body weight and achieving glycemic control in patients with type 2 diabetes and obesity?}

- Behavioral therapy needs to be combined with lifestyle modification to achieve and maintain weight reduction over the long term in patients with type 2 diabetes and obesity [4]. Obesity is associated with abnormal eating behavior such as speed eating characterized, by an excessive intake of energy over a short time, and impulse eating, and eating between meals from post-lunch to nighttime can be problematic in many of these patients. Thus, when their treatment goals have been determined, these patients must be monitored and their overeating behavior should be evaluated through diet journals and body weight measurements to establish improvements in their eating behavior. Behavioral enhancement, such as through the implementation of routine motivation measures, is thought to be effective in maintaining desired behavioral changes. However, there is currently no clear evidence to support the effectiveness of behavioral therapy in the achievement of glycemic control in patients with type 2 diabetes and obesity.

\section{Q14-5 Is pharmacotherapy effective for achieving glycemic control in patients with type 2 diabetes and obesity?}

- The use of insulin or SUs is to be minimized in patients with type 2 diabetes and obesity, given that their uncritical use may promote obesity [3].

- Medications associated with weight gain include (in addition to insulin and SUs) rapid-acting insulin secretagogues (glinides), thiazolidinediones (TZDs), tricyclic antidepressants (amitriptyline), and atypical antipsychotic agents (olanzapine). The use of these drugs by patients with type 2 diabetes and obesity warrants caution [3].

- The appetite-inhibitory and weight-reducing properties of glucagon-like peptide 1 (GLP-1) receptor agonists may improve glycemic control in patients with type 2 diabetes and obesity [3]. Indeed, some GLP-1 receptor agonists are currently being used to treat obesity overseas.

\section{CQ14-6 Is surgical therapy effective for patients with type 2 diabetes and high-degree obesity?}

- The role of obesity surgery has drawn attention. Obesity surgery includes not only bariatric surgery for high-degree obesity, but also metabolic surgery, which improves diabetes or prevents the onset/progression of the disease. Thus, obesity surgery is an effective treatment option for patients with type 2 diabetes and obesity who are less amenable to weight reduction [5] (grade B: $100 \%$ agreement). 


\section{Q14-7 What is metabolic syndrome?}

- Metabolic syndrome is defined as a condition that involves any two of the following conditions, in addition to visceral fat accumulation (visceral fat area $\geq 100 \mathrm{~m}^{2}$ on CT measurement at the level of the umbilicus): fasting hyperglycemia $\geq 110 \mathrm{mg} / \mathrm{dL}$ (6.1 mmol/l), dyslipidemia such as hypertriglyceridemia ( $\geq 150 \mathrm{mg} / \mathrm{dL})$, hypo highdensity lipoprotein (HDL) cholesterolemia $(<40 \mathrm{mg} / \mathrm{dL})$, and high blood pressure $(\geq 130 / 85 \mathrm{mmHg})$ [6].

\section{Hypertension associated with diabetes}

\section{Q15-1 Is hypertension a risk factor for macroangiopathy in patients with diabetes?}

- Both diabetes and hypertension are established risk factors for atherosclerosis-associated macroangiopathy; furthermore, patients with diabetes and hypertension have a higher incidence of macroangiopathy and a poorer prognosis [1].

\section{Q15-2 Is hypertension a risk factor for microangiopathy in patients with diabetes?}

- Hypertension in patients with diabetes represents a risk factor for microangiopathy, such as diabetic nephropathy, retinopathy and neuropathy [2].

- The correction of hypertension potentially prevents the progression of diabetic nephropathy in patients with diabetes [3].

- Angiotensin II receptor antagonists (ARBs) and angiotensin-converting enzyme (ACE) inhibitors potentially prevent the progression of microangiopathy [3, 4].

\section{Q15-3 What is the office blood pressure threshold for initiating antihypertensive therapy in patients with diabetes? (Fig. 6)}

- The initiation antihypertensive therapy is deemed to be appropriate for patients with an office blood pressure of $\geq 130 / 80 \mathrm{mmHg}$.

- Intervention with antihypertensive agents is to be immediately initiated for patients with an office blood pressure of $\geq 140 / 90 \mathrm{mmHg}$.
Fig. 6 The treatment of hypertension complicating diabetes mellitus. Excerpt from: The Japanese Society of Hypertension, Guidelines for the Treatment of Hypertension, 2014, P.78
Blood pressure on initiation of treatment entry : $\geq 130 / 80 \mathrm{mmHg}$

Start antihypertensive treatment simultaneously with lifestyle modification/glycemic control.

1) Those with blood pressure $140 / 90 \mathrm{mmHg}$ : Start antihypertensive drug therapy.

2) Those with blood pressure $130-139 / 80-89 \mathrm{mmHg}$ : In those in whom lifestyle modification is thought to be likely to result in decreased blood pressure, lifestyle modification may be attempted for up to 3 months. If their blood pressure value after modification is $130 / 80 \mathrm{mmHg}$, they should be clinically diagnosed as having hypertension and antihypertensive therapy should be initiated.

Improvement on lifestyle, blood glucose management together with pharmaceutical treatment*

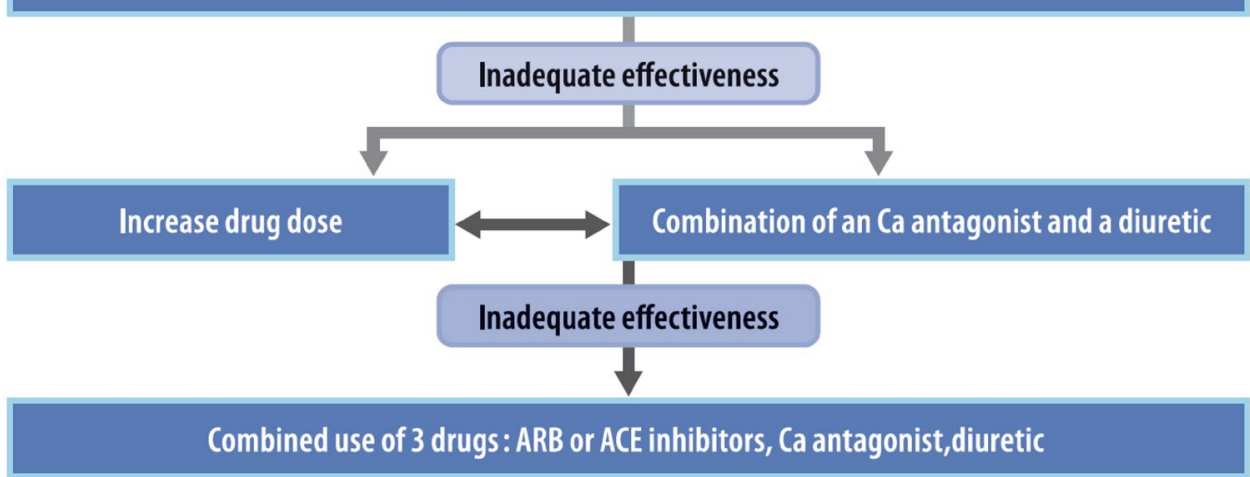

Blood pressure target $<130 / 80 \mathrm{mmHg}^{*}$ 
- Lifestyle modification (lasting no more than 3 months) may be indicated for patients with diabetes and an office blood pressure of 130-139/80-89 mmHg if such modification is expected to achieve the patient's blood pressure goal; however, antihypertensive agents are to be initiated immediately when such modification is considered to be unlikely to achieve the blood pressure goal.

- Home blood pressure measurement is strongly recommended and home blood pressure measurement should be performed prior to office blood pressure measurement when there is discrepancy between the home and office blood pressure readings.

- A home blood pressure of $\geq 125 / 75 \mathrm{mmHg}$ is deemed to be an appropriate level for initiating intervention in patients with diabetes (Consensus between the Japanese Society of Hypertension and the Japan Diabetes Society).

\section{CQ15-4 Is controlling office blood pressure to $<130 / 80 \mathrm{mmHg}$ effective in preventing the onset of complications in patients with diabetes and hypertension?}

- A blood pressure of $<130 / 80 \mathrm{mmHg}$ deemed to be appropriate as the office blood pressure goal for preventing complications in patients with diabetes and hypertension [5,6] (grade B: 90\% agreement).

- While controlling blood pressure to the blood pressure goal is effective in preventing diabetic complications, particularly cerebrovascular disease, sufficient attention should be paid to the potential for organ hypoperfusion in association with decreased blood pressure in patients with diabetes and atherosclerotic coronary disease or peripheral artery disease, or in older patients with diabetes [7, 8] (grade B: 100\% agreement) (consensus between the Japanese Society of Hypertension and the Japan Diabetes Society).

CQ15-5 Are angiotensin-converting enzyme (ACE) inhibitors or angiotensin II receptor antagonists (ARBs) used as first-line antihypertensive medications for patients with diabetes and hypertension?

- ACE inhibitors or ARBs are to be used as first-line antihypertensive drugs in patients with diabetes and hypertension, given their organ-protective and insulinsensitizing properties $[9,10]$ (grade A: $100 \%$ agreement) (consensus between the Japanese Society of Hypertension and the Japan Diabetes Society).
Q15-6 Which is preferable, a calcium channel blocker (CCB) or a diuretic, as an add-on agent in patients with diabetes and hypertension

- A calcium channel blocker or a low-dose thiazide diuretic is to be added or combination therapy with three agents is to be implemented when treating diabetic patients whose blood pressure is less well controlled with an ACE inhibitor/ARB (consensus between the Japanese Society of Hypertension and the Japan Diabetes Society).

\section{Dyslipidemia associated with diabetes}

\section{Q16-1 Is dyslipidemia a risk factor} for macroangiopathy in diabetes?

- Dyslipidemia is a risk factor for macroangiopathy [1].

- Hyper-low-density-lipoprotein (LDL)-cholesterolemia is a strong risk factor for coronary artery disease [2].

\section{Q16-2 Is dyslipidemia a risk factor} for microangiopathy in diabetes?

- Hypertriglyceridemia is a risk factor for microangiopathy [3].

- Hypo high-density lipoprotein (HDL) cholesterolemia is a risk factor for microangiopathy [4].

\section{Q16-3 What are the threshold for initiating antidyslipidemic therapy and its control goals in diabetes? (Table 5)}

- The primary goal of antidyslipidemic therapy is to control the LDL-cholesterol level to: $<100 \mathrm{mg} / \mathrm{dL}$ in patients with a history of coronary artery disease and

Table 5 The lipid control target values in patients with diabetes. Edited by Japan Atherosclerosis Society: Guidelines for Prevention of Atherosclerotic Cardiovascular Diseases, published 2012, p. 42

\begin{tabular}{lllll}
\hline $\begin{array}{l}\text { Coronary artery } \\
\text { disease }\end{array}$ & \multicolumn{4}{l}{ Lipid control target values $(\mathrm{mg} / \mathrm{dL})$} \\
\cline { 2 - 4 } & LDL-C & HDL-C & TG & Non-HDL-C \\
\hline Present & $<120$ & & $<150$ \\
Absent & $<100$ & & $<150$ & \\
\hline
\end{tabular}


to $<120 \mathrm{mg} / \mathrm{dL}$ in patients without a history of coronary artery disease.

- The control goal for fasting triglyceride (TG) is $<150 \mathrm{mg} / \mathrm{dL}$.

- The control goal for HDL cholesterol is $\geq 40 \mathrm{mg} / \mathrm{dL}$.

\section{CQ16-4 Is MNT effective against dyslipidemia in patients with diabetes?}

- MNT has been shown to be effective against dyslipidemia in patients with diabetes [5] (grade A: 100\% agreement).

- The intake of polyunsaturated fatty acids (PUFA) is recommended [6] (grade A: 100\% agreement).

\section{CQ16-5 Is physical activity/exercise effective against dyslipidemia in patients with diabetes?}

- Physical activity/exercise has been shown to be effective against dyslipidemia in patients with diabetes [7] (grade A: $100 \%$ agreement).

\section{CQ16-6 Is statin therapy effective in reducing the risk of cardiovascular disease (CVD) or mortality in patients with diabetes and dyslipidemia?}

- The use of statins has been shown to reduce the risk of CVD and mortality in patients with diabetes and dyslipidemia [8] [level of recommendation: A (100\% consensus)].

- Statins are the drugs of choice for hyper-LDL-cholesterolemia in patients with diabetes [9] (grade A: 100\% agreement).

\section{CQ16-7 Is the use of non-statin drugs effective in reducing the risk of CVD or mortality in patients with diabetes and dyslipidemia?}

- The use of fibrates has been shown to reduce the risk of non-fatal CVD in patients with diabetes and dyslipidemia [10] (grade B: 100\% agreement).

- The use of fibrates is to be considered for patients with diabetes and hypertriglyceridemia [11] (grade B: 100\% agreement).

\section{Impaired glucose metabolism in pregnancy}

\section{CQ17-1 Does glycemic control before and during pregnancy lead to improvements in the maternal and neonatal prognosis?}

- While poor glycemic control before and during early phase pregnancy has been shown to be associated with an increased incidence of congenital anomalies and fetal death, strict glycemic control from well before pregnancy has been shown to be associated with a reduced incidence of these complications [1] (grade A: 95\% agreement).

- While poor glycemic control during pregnancy has been shown to be associated with an increased risk of perinatal complications, including fetal macrosomia, strict glycemic control during pregnancy has been shown to be associated with a reduction in the risk of these complications [2] (grade A: 100\% agreement).

\section{Q17-2 How are hyperglycemic disorders diagnosed in pregnancy? (Table 6)}

- Hyperglycemic disorders in pregnancy include: (1) gestational diabetes mellitus (GDM), (2) overt diabetes in pregnancy, and (3) pre-gestational diabetes mellitus, and are diagnosed based on $75 \mathrm{~g}$ oral glucose tolerance tests (OGTTs), HbA1c values and the clinical findings [4].

\section{Q17-3 How should patients with diabetes be managed and treated before pregnancy?}

- Patients with diabetes who wish to become pregnant are to be fully informed about the importance of strict glycemic control being implemented from well before pregnancy to prevent congenital anomalies, fetal death and miscarriage due to poor glycemic control [1].

- Every effort should be made to achieve glycemic control that is as close to normal as possible while at the same time avoiding hypoglycemia in these patients [1].

- Given that oral glucose-lowering agents are not recommended in patients who wish to become pregnant, insulin therapy is to be implemented if glycemic control is deemed inadequate despite MNT [1].

- All patients with diabetes who wish to become pregnant are to be evaluated for diabetic complications. If complications are present, they should be managed from well before pregnancy, as they have been shown to adversely 
Table 6 Gestational diabetes mellitus: its definition and diagnostic criteria

\begin{tabular}{|c|c|}
\hline Definition & $\begin{array}{l}\text { Gestational diabetes mellitus is defined as a state of pre-diabetic impaired glucose tolerance which is identi- } \\
\text { fied or which occurs for the first time during pregnancy and which does not include overt diabetes in } \\
\text { pregnancy or pregnancy complicated by diabetes (pre-gestational diabetes mellitus) }\end{array}$ \\
\hline \multicolumn{2}{|l|}{ Diagnostic criteria } \\
\hline Gestational diabetes mellitus & $\begin{array}{l}\text { Individuals are to be diagnosed with gestational diabetes mellitus if they meet any of the following criteria in } \\
\text { a } 75 \mathrm{~g} \text { oral glucose tolerance test }(\mathrm{OGTT}) \text { : } \\
\text { (1) Fasting glucose value: } \geq 92 \mathrm{mg} / \mathrm{dL}(5.1 \mathrm{mmol} / \mathrm{L}) \\
\text { (2) } 1 \text {-h post-OGTT glucose value: } \geq 180 \mathrm{mg} / \mathrm{dL}(10.0 \mathrm{mmol} / \mathrm{L}) \\
\text { (3) 2-h post-OGTT glucose value: } \geq 153 \mathrm{mg} / \mathrm{dL}(8.5 \mathrm{mmol} / \mathrm{L})\end{array}$ \\
\hline Overt diabetes in pregnancy ${ }^{\mathrm{a}}$ & $\begin{array}{l}\text { Individuals are to be diagnosed with overt diabetes in pregnancy if they meet either of the following during } \\
\text { pregnancy: } \\
\text { (1) Fasting glucose: } \geq 126 \mathrm{mg} / \mathrm{dL}(7.0 \mathrm{mmol} / \mathrm{L}) \\
\text { (2) HbAlc: } \geq 6.5 \% \\
* \text { Individuals with casual glucose values of } \geq 200 \mathrm{mg} / \mathrm{dL}(11.1 \mathrm{mmol} / \mathrm{L}) \text { or } 2 \text {-h post- } 75 \mathrm{~g} \text { OGTT glucose } \\
\text { values of } \geq 200 \mathrm{mg} / \mathrm{dL}(11.1 \mathrm{mmol} / \mathrm{L}) \text { in pregnancy are to be examined to see if they meet either (1) or (2) } \\
\text { with the potential diagnosis of overt diabetes in pregnancy in mind }{ }^{\mathrm{b}}\end{array}$ \\
\hline Pre-gestational diabetes mellitus & $\begin{array}{l}\text { Individuals are to be diagnosed with pre-gestational diabetes mellitus if they meet either of the following: } \\
\text { (1) Diabetes mellitus diagnosed before pregnancy } \\
\text { (2) Pregnancy associated with unequivocal evidence of diabetic retinopathy }\end{array}$ \\
\hline
\end{tabular}

${ }^{a}$ Overt diabetes mellitus in pregnancy includes diabetes mellitus overlooked before pregnancy, impaired glucose tolerance resulting from changes in glucose metabolism during pregnancy and type 1 diabetes mellitus occurring during pregnancy. In either case, the diagnosis needs to be confirmed in affected individuals after delivery

${ }^{\mathrm{b}}$ Individuals are expected to show higher post-OGTT glucose values during pregnancy than usual, reflecting increased physiological insulin resistance during pregnancy, particularly in later stage. Thus, the casual glucose and post-75 g OGTT values defined in the diagnostic criteria for diabetes mellitus during non-pregnancy are not readily applicable (adapted from [11])

affect the maternal prognosis and pregnancy outcomes [3].

- Careful family planning is to be recommended for patients who wish to become pregnant and the patient is to be fully informed about the potential need for contraception, to avoid congenital anomalies and miscarriage and to ensure healthy neonatal development and a favorable long-term maternal prognosis [1].

- All patients with diabetes who wish to become pregnant are to be evaluated for their use of antihypertensive and lipid-lowering agents; these agents are to be reconsidered in view of pregnancy.

\section{Q17-4 How should diabetic retinopathy be managed and treated before and during pregnancy?}

- Diabetic retinopathy has been shown to worsen during pregnancy and after delivery. Thus, those who wish to become pregnant should be evaluated for glycemic control and diabetic retinopathy. If present, diabetic retinopathy is to be managed from well before pregnancy. Given that pre-proliferative/proliferative retinopathy is more likely to worsen, patients with either form of retinopathy are to be instructed to attempt to conceive only after their disease has become stable with ophthalmologic treatment [5].

\section{Q17-5 How should diabetic nephropathy be managed and treated before and during pregnancy?}

- Diabetic nephropathy during pregnancy has been shown to lead not only to the onset of pregnancy-induced hypertension, premature delivery, and renal dysfunction in mothers, but also to growth retardation in their infants. Thus, the condition represents a high-risk for both the mother and baby [3].

- When a patient indicates a wish to become pregnant, their renal function is to be evaluated based on urinary albumin/protein, the glomerular filtration rate (GFR), and creatinine clearance $(\mathrm{Ccr})$, from well before pregnancy [6].

- Given that pregnancy has been shown to be associated with a further worsening of the renal function-likely leading to poor perinatal prognosis in patients with renal impairment-patients with renal impairment are to be fully informed about these risks before pregnancy and those who become pregnant are to be given careful counseling as to whether to continue pregnancy [6]. 


\section{Q17-6 How pregnant women are screened for gestational diabetes mellitus (GDM)?}

- Given that screening for gestational diabetes mellitus (GDM), based on risk factors, such as a family history of diabetes, obesity, a history of fetal macrosomia and age, is thought likely to lead to many patients with GDM being missed, it is preferable that all pregnant women be consistently screened for GDM, based on a glucosebased assessment including casual and fasting glucose measurements and a glucose challenge test (GCT); ideally, at first consultation and at between 24 and 28 weeks of gestation [7].

\section{Q17-7 How should glycemic control be implemented in cases involving hyperglycemic disorders during pregnancy}

- Glycemic control in pregnant women with hyperglycemic disorders is intended to control their glucose to as close to that of a healthy pregnant woman as possible, while minimizing the incidence of hypoglycemia; the target fasting glucose level is $70-100 \mathrm{mg} / \mathrm{dL}(3.9-5.6 \mathrm{mmol} / \mathrm{L})$ and the target postprandial 2-h level is $<120 \mathrm{mg} / \mathrm{dL}$ $(6.7 \mathrm{mmol} / \mathrm{L})$.

- MNT in pregnant women with hyperglycemic disorders involves not only providing necessary and sufficient nutrition for healthy fetal development, but also ensuring strict glycemic control and appropriate weight gain [8].

- Insulin therapy is to be implemented if patient's glycemic control goal is not achievable with MNT. Intensive insulin therapy, which involves self-monitoring of blood glucose (SMBG), is to be employed to better ensure sustained glycemic control [9].

- While there is a paucity of evidence to support the usefulness of increased physical activity/exercise in the management of hyperglycemic disorders in pregnancy, increased physical activity/exercise may have a role to play in promoting health including improving maternal glycemic control, suppressing excessive weight gain, and providing a change of pace.

\section{Q17-8 How should delivery be managed in pregnant women with impaired glucose metabolism?}

- While vaginal delivery represents the standard approach in women with hyperglycemic disorders as in healthy pregnancy, the approach should be individualized, with consideration given to fetal growth and wellbeing.

- Given that maternal hyperglycemia is a risk factor for neonatal hypoglycemia, the maternal glucose level at delivery is to be maintained at $\leq 100 \mathrm{mg} / \mathrm{dL}$ $(5.6 \mathrm{mmol} / \mathrm{L})$ in pregnant patients with hyperglycemic disorders.

\section{Q17-9 How should patients with gestational diabetes mellitus (GDM) or overt diabetes during pregnancy be evaluated and managed after delivery?}

- Patients with gestational diabetes mellitus (GDM), who are at high-risk of developing impaired glucose tolerance (IGT) after delivery [10], need to be evaluated for glucose metabolism from early in the post-partum period with a $75 \mathrm{~g}$ OGTT performed at between 6 and 12 weeks post-delivery. Thereafter, they should be followed up on a routine basis, but instructed on MNT and increased physical activity/exercise as required.

\section{Pediatric/adolescent diabetes}

\section{Q18-1 What is the basic treatment policy} for pediatric/adolescent diabetes?

- The treatment policy for pediatric/adolescent patients with diabetes is to accommodate age-specific differences in development/growth and comprehension, with sufficient consideration given to the patient's mental immaturity $[1,2]$.

\section{Q18-2 How is pediatric/adolescent type 1 diabetes diagnosed?}

- The diagnosis of pediatric/adolescent type 1 diabetes consists of demonstrating evidence of progressively declining endogenous insulin secretion or its depletion; islet-specific autoantibodies have been shown to be present in the majority $(70-90 \%)$ of patients [3]. 


\section{Q18-3 How are pediatric/adolescent patients with type 1 diabetes to be treated?}

- The goal of treatment consists of preventing diabetic complications through glycemic control as well as maintaining the patient's social and mental wellbeing $[1,2]$.

- In pediatric/adolescent patients with type 1 diabetes, insulin injection therapy is indispensable and is therefore to be initiated immediately after the diagnosis has been established [1,2].

- MNT in pediatric/adolescent patients with type 1 diabetes is not primarily intended to restrict the energy intake but rather to ensure the age- and gender-specific intake of energy that is necessary and sufficient for their normal development and growth [1,2].

- All types of sport are recommended as physical activity/exercise for pediatric/adolescent patients with type 1 diabetes as long as they have no advanced complications and their glycemic control remains stable [1,2].

- Hypoglycemia is likely to be associated with cognitive impairment. However, hypoglycemia may not be recognized in patients below 6-7 years of age and may therefore become severe. Thus, countermeasures need to be taken against hypoglycemia in these patients. It should also be noted that persistent hyperglycemia is also associated with cognitive impairment [4].

\section{Q18-4 How is type 2 diabetes diagnosed in pediatric/adolescent patients?}

- An oral glucose tolerance test (OGTT) using glucose (body weight $\times 1.75$ ) g (ideal body weight may also be used; up to a maximum of $75 \mathrm{~g}$ ) is to be performed in pediatric/adolescent patients and their diagnosis is to be made according to the same glucose categories and diagnostic criteria that are used in adult patients [1].

\section{Q18-5 How are pediatric/adolescent patients with type 2 diabetes to be treated?}

- As in patients with type 1 diabetes, the goal of treatment consists of preventing chronic diabetic complications through glycemic control as well as in maintaining their social and mental wellbeing [1, 5]. Again, early intervention for multiple risk factors is the key to preventing micro and macroangiopathy in these patients.

- MNT in pediatric/adolescent patients with type 2 diabetes is not primarily intended to restrict the energy intake but rather to ensure the age- and gender-specific intake of energy that is necessary and sufficient for their normal development and growth $[1,5]$. In obese individuals, however, the energy intake is to be limited to $90-95 \%$ of the intake required for their ideal body weight and to be nutritionally well-balanced $[1,6]$, while increased physical activity/exercise in these individuals is to primarily involve aerobic exercise, thus increasing both their physical activity levels and their energy consumption $[1,6]$.

- In patients with inadequate glycemic control despite MNT and physical activity/exercise, pharmacotherapy is to be initiated $[1,5]$. In patients with ketoacidosis or those with inadequate glycemic control despite pharmacotherapy, insulin therapy is to be initiated $[1,5]$. In patients with hypertension and dyslipidemia, appropriate therapy is to be implemented for these conditions $[1,5]$.

\section{Q18-6 How is neonatal diabetes diagnosed and treated?}

- Neonatal diabetes is broadly classified into transient and persistent phenotypes; their diagnosis entails testing for the respective responsible genes [7].

- Sulfonylureas (SUs) have been shown to be effective in treating patients with KCNJ11/ABCCB8 gene mutations and to allow these patients to discontinue insulin therapy $[8,9]$.

\section{Q18-7 How are pediatric/adolescent patients and their families to be supported?}

- Pediatric/adolescent patients are to be given optimal therapy, even at school $[1,10]$.

- Pediatric/adolescent patients are to participate in all school events and school administrators are to ensure that their schools provide support for their participation [10].

- Given that mental/psychological factors have been shown to significantly affect the patient's diabetes management and prognosis, mental/psychological counseling is to be offered with sufficient care given to addressing individual differences in mental/psychological maturity [11, 12].

- Immediately after affected patients have been diagnosed, their families are to be fully instructed on their diabetes as well as the treatment policy decided on to address their individual maturity [10].

- Diabetes camps are intended to offer support for pediatric patients to grow into independent adults and include medically designed and recreational programs [1]. 


\section{Diabetes in older adults}

\section{Q19-1 What are the characteristics of diabetes in older adults?}

- Older patients with diabetes are likely to be susceptible to postprandial hyperglycemia and hypoglycemia and to be particularly vulnerable to hypoglycemia.

- In patients with diabetes, older age tend to be associated with renal impairment, which makes older patients susceptible to drug interactions.

- In patients with diabetes, older age is often associated with geriatric syndromes such as dementia/cognitive impairment, depression and sarcopenia.
CQ19-2 Is glycemic control effective in suppressing vascular complications in older patients with diabetes? (Fig. 7)

- Given that hyperglycemia is a risk factor for both diabetic micro- and macroangiopathy in older patients as well, appropriate glycemic control is to be implemented in these patients $[1,2]$ (grade A by consensus: $100 \%$ agreement).
Fig. 7 Glycemic targets (HbA1c values) for older patients with diabetes

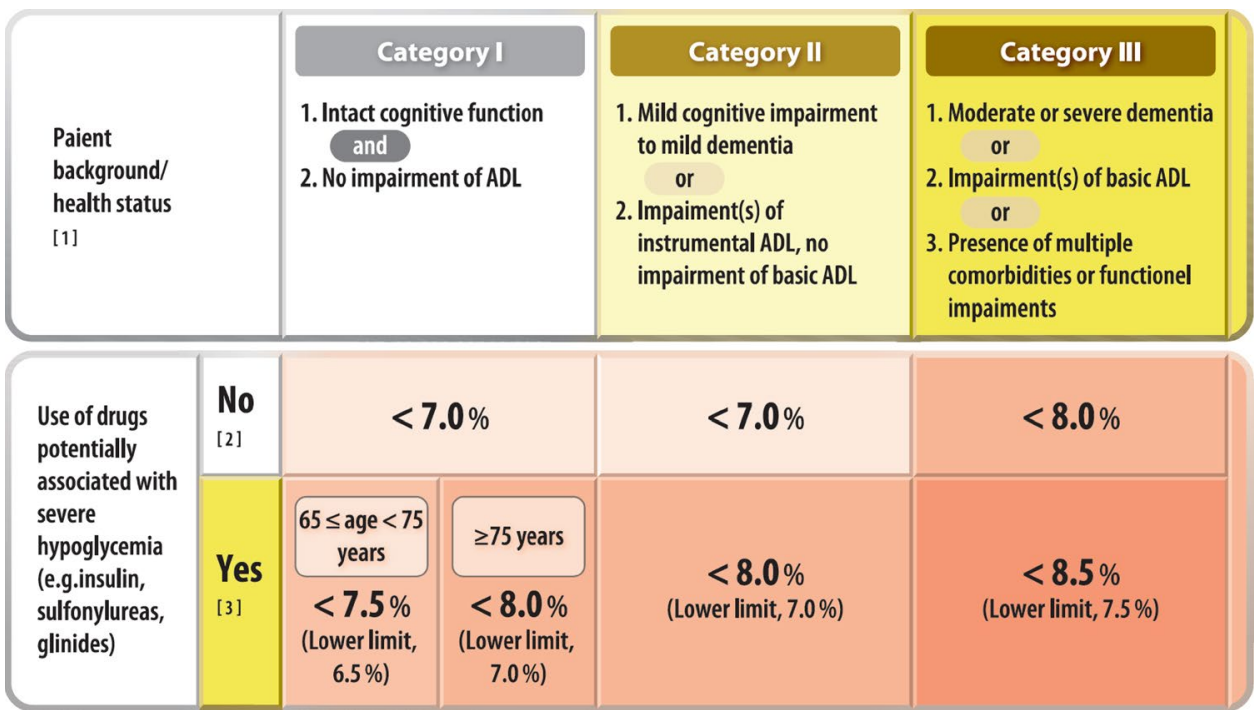

For older patients, the glycemic target is to be determined for each patient by taking into account his/her age, duration of diabetes, risk of hypoglycemia, and any support available to the patient, as well as the patient's cognitive function, basic/instrumental activities of daily living (ADL), and comorbidities/functional impairments, while noting the potential risk of hypoglycemia that increases with age in each patient

(1) Refer to the Japan Geriatrics Society website [11,12], for the evaluation of the cognitive function, basic ADL (e.g., self-care abilities such as dressing, transferring, bathing, and toileting), and instrumental ADL (e.g., the patient's ability to maintain an independent household by performing activities such as shopping, meal preparation, taking medication, and handling finances). In end-of-life care, priority is to be given to preventing significant hyperglycemia and subsequent dehydration and acute complications through appropriate therapeutic measures. (2) As in other age groups, the glycemic target for preventing diabetic complications in older patients with diabetes is set to $<7.0 \%$. However, this can be set to $<6.0 \%$ for those who are thought to be likely to achieve glycemic control through MNT and/or physical activity/exercise alone or those who are likely to achieve glycemic control with drug therapy without adverse reactions, or $8.0 \%$ for those in whom intensifying therapy may prove difficult. In either case, no lower limit is specified for the glycemic target. A glycemic target of $<8.5 \%$ may be allowed in patients who are thought to be in category III and therefore at risk of developing adverse reactions to multi-drug combination therapy or in those with serious comorbidities or poor social support. (3) In patients in whom priority should be given to preventing the onset/progression of diabetic complications due to their duration of disease, the glycemic target or its lower limit may be set for each older patient with appropriate measures in place to prevent severe hypoglycemia. Current treatments are to be continued in those who are $<65$ years of age, even when their HbA1c values fall below their glycemic target or a lower limit while on therapy; however, care needs to be taken to monitor these patients for potential severe hypoglycemia. Glinides may be classified as drugs that are unlikely to be associated with severe hypoglycemia, as the onset of severe hypoglycemia varies depending on the type and amount of glinide used in a particular patient relative to the patient's glucose level. 
Q19-3 Are hyperglycemia and hypoglycemia risk factors for cognitive impairment, dementia, decreased activities of daily living (ADL) and depression in older patients?

- Hyperglycemia and severe hypoglycemia are risk factors for cognitive impairment and dementia in older patients $[3,4]$.

- Hyperglycemia is a risk factor for sarcopenia, falls and depression in older patients [5], while decreased HbA1c [6] and hypoglycemia [7] are associated with an increased risk of falls in these patients.

- Given that there is no clear evidence to show that reducing glucose levels leads to the prevention of dementia [8] or decreased ADL [6], tight glycemic control should not be implemented in older patients.

\section{Q19-4 Is MNT effective for achieving glycemic control in older patients with diabetes?}

- MNT has also been shown to be useful for correcting hyperglycemia, dyslipidemia, and obesity in older patients.

\section{CQ19-5 Is physical activity/exercise effective for achieving glycemic control and maintaining the ADL and cognitive function of older patients with diabetes?}

- Physical activity/exercise (i.e., routine physical activity and walking) has been shown not only correct metabolic disorders but also improve the life prognosis, reduce cardiovascular disease, maintain ADL, and suppress cognitive impairment [9] (grade A: 100\% agreement).

- Resistance training has been shown to increase the lean body mass and muscle strength and improve glycemic control in older patients with type 2 diabetes [10] (grade B: $100 \%$ agreement).

\section{Q19-6 What are the precautions in implementing glucose-lowering therapy in older patients?}

- Older patients receiving glucose-lowering agent(s) are to be monitored for associated adverse events such as hypoglycemia and their families and caregivers are to be instructed on nonspecific symptoms of hypoglycemia and how to handle them as well as how to deal with sick days.
- The glucose-lowering agents that are to treat older patients are to be chosen with consideration given to their physical and cognitive function, socioeconomic status, adherence and their (or their caregiver's) wishes and preferences.

- The renal function of older patients is to be regularly assessed and their medications are to be replaced or their doses adjusted accordingly.

\section{Q19-7 Are hypertension and dyslipidemia risk factors for other complications in older patients with diabetes?}

- Hypertension is likely to be a risk factor for micro- and macroangiopathy and dyslipidemia is likely to be a risk factor for macroangiopathy in older patients with diabetes.

\section{Acute metabolic complications of diabetes, sick days, and infectious diseases}

\section{Q20-1 How is diabetic ketoacidosis (DKA) diagnosed and treated?}

- Diabetic ketoacidosis (DKA) is defined as a state that occurs as a consequence of inadequate insulin action and increased insulin-counterregulatory hormone secretion and which requires emergency attention due to associated hyperglycemia [ $>250 \mathrm{mg} / \mathrm{dL}$ (13.9 mmol/L)], ketosis (increased $\beta$-hydroxybutyric acid), acidosis (arterial blood $\mathrm{pH}, \leq 7.30$; bicarbonate ion $\left.\left[\mathrm{HCO}_{3}^{-}\right], \leq 18 \mathrm{mEq} / \mathrm{L}\right)[1,2]$.

- Patients presenting with DKA are to be appropriately managed with normal saline-based fluid and electrolyte (e.g., sodium chloride and potassium) replacement as required [1].

- As a rule, acidosis is not to be corrected in patients with DKA [1, 2].

- Patients presenting with DKA are to be given regular insulin as continuous intravenous insulin infusions $[1,2]$.

- The use of bolus insulin injection in children is associated with the risk of cerebral edema and is not recommended [3]. 


\section{Q20-2 How is a hyperosmolar hyperglycemic state (HHS) diagnosed and treated?}

- A hyperosmolar hyperglycemic state (HHS) is associated with hyperglycemia [> $600 \mathrm{mg} / \mathrm{dL}(33.3 \mathrm{mmol} / \mathrm{L})]$ and hyperosmolarity (effective osmolality, > $320 \mathrm{mOsm} / \mathrm{L}$ ) and potentially mild ketosis (if present), but not severe ketoacidosis (arterial blood $\mathrm{pH}>7.30$; $\left.\mathrm{HCO}_{3}{ }^{-}, \leq 18 \mathrm{mEq} / \mathrm{L}\right)$ [2].

- Patients presenting with HHS are to be appropriately managed with normal saline-based fluid and electrolyte replacement as required [2].

- As in DKA, patients presenting with HHS are to be given regular insulin as continuous intravenous insulin infusions [2].

\section{Q20-3 How is lactic acidosis (LA) diagnosed and treated?}

- Lactic acidosis (LA) is defined as a state of metabolic acidosis (arterial blood pH, < 7.35) due to the presence of a markedly increased lactic acid concentration ( $\geq 5.0 \mathrm{mmol} / \mathrm{L}$ ) resulting from the overproduction or metabolic dysregulation of lactic acid and requires emergency attention [4].

- Although LA is reported in patients receiving biguanides, the majority of these cases occur in patients for whom biguanides should have been contraindicated or used with caution $[5,6]$.

- Patients with LA should be treated for any underlying disease [4].

- In patients with LA, sufficient tissue blood flow and oxygenation should be ensured with oxygen supplementation, artificial respiration, extracellular fluid replacement or vasopressor therapy, as required [4].

\section{Q20-4 How is hypoglycemia managed?}

- Patients exhibiting hypoglycemic symptoms, such as palpitation, sweating, weakness or a decreased level of consciousness, or those with a usual glucose level of $<70 \mathrm{mg} / \mathrm{dL}$ (3.9 mmol/L) should be diagnosed as having hypoglycemia and managed accordingly [7].

- Patients with hypoglycemia should be managed with oral carbohydrates (equivalent to glucose 5-10 g), intravenous glucose infusion (equivalent to glucose 10-20 g), or muscular glucagon injection. Hypoglycemia may recur or be prolonged, even after the resolution of symptoms and therefore needs to be closely monitored and managed [8].
Q20-5 Are any infections typically associated with diabetes?

- Infections such as emphysematous cholecystitis, organ or soft tissue abscesses, rhinocerebral mucormycosis, malignant external otitis, emphysematous cystitis, emphysematous pyelitis, necrotizing fasciitis and Fournier's gangrene tend to have diabetes as an underlying disease [9].

\section{Q20-6 How is glycemic control managed during infection?}

- Diabetes is associated with decreased multinuclear neutrophil migration, adhesion, phagocytic and bactericidal capacity. Thus, infections tend to persist and become severe in patients with poor glycemic control.

- Hyperglycemia should be treated with insulin therapy in patients with a severe infection $[7,10,11]$. These patients must also be managed not only with fluid replacement and continuous intravenous insulin infusion, but also with immediate treatment of any underlying disease responsible for hyperglycemia from an early stage onwards (the primary infection site and the causative bacteria are to be identified and appropriate agents are to be chosen for the pathogen) [11].

\section{Q20-7 Is vaccination recommended in patients with diabetes?}

- Influenza vaccination is recommended for patients with diabetes [12].

- Pneumococcal vaccination is recommended for patients with diabetes [13].

\section{Q20-8 How are sick days to be managed?}

- Patients with diabetes should be encouraged to establish a connection with healthcare facilities ahead of time to ensure that they will be available for consultation during sick days [14].

- Patients with diabetes are to be instructed not to discontinue oral hypoglycemic agents or insulin without their physicians' instruction [14].

- When they have any problems with eating, patients with diabetes are to be encouraged to consult healthcare facilities early and to receive appropriate instructions [14].

- Care is to be taken to make sure that patients with diabetes have a sufficient water intake to prevent potential 
dehydration and that they consume a sufficient amount of easily digestible carbohydrates (e.g., porridge, noodles and fruit juice) to ensure a sufficient intake of energy [14] during sick days.

- Patients with diabetes are to be instructed to self-monitor their glucose levels and to have their ketone body levels measured as frequently as possible during sick days [14].

\section{Prevention of type 2 diabetes}

\section{Q21-1 How are patients assessed to determine their risk of diabetes?}

- Various risk factors have been identified for diabetes, and a risk model (risk scores) is currently being developed for type 2 diabetes in Japanese [1-3].

\section{Q21-2 Are obesity and changes in body composition associated with the risk of type 2 diabetes?}

- Obesity and abdominal obesity [4], weight gain [5, 6], and low birthweight [7, 8] are associated with an increased risk of diabetes.

\section{Q21-3 Are physical activity and exercise habits associated with the risk of diabetes?}

- Strenuous physical activity in daily living [9], aerobic exercises such as walking [10] and exercise habits such as resistance-exercise training $[11,12]$ are associated with a decreased risk of diabetes.

\section{Q21-4 Is the total energy and nutrient intake associated with the risk of diabetes?}

- Modification of dietary habits focusing on optimization of the total energy intake is crucial to prevent type 2 diabetes [13-15]. An insufficient intake of dietary fibers has been shown to be a risk factor for type 2 diabetes [16, 17].
Q21-5 Does the intake of alcoholic and other beverages affect the risk of type 2 diabetes?

- Evidence from observational studies shows a U-shaped correlation between the intake of alcohol and the risk of diabetes [18, 19]. Thus, the intake of alcohol is to be limited to within a reasonable range (equivalent to 20-25 g of ethanol per day) [20-22]. The intake of soft drinks [23, 24] has been shown to be associated with an increased risk of diabetes. While the intake of coffee is highly likely to have a preventive effect against the development of diabetes, the available evidence to support this is not strong enough to include it among the recommendations.

\section{Q21-6 Do smoking and smoking cessation affect the risk of type 2 diabetes?}

- Smoking is an established risk factor for diabetes [26]. Smoking cessation is temporarily associated with increased risk of diabetes due to associated weight gain, but is associated with a decreased risk of diabetes over the long term [27, 28].

\section{Q21-7 Are psychosocial factors, such as stress and working environment, associated with the risk of type 2 diabetes?}

- Mental stress [25] and depressive tendencies (depression) $[29,30]$ are associated with an increased risk of diabetes. Working environmental factors, such as short sleep duration [31] and shift work [32], are also risk factors for diabetes.

\section{CQ21-8 Does intervention with lifestyle modification prevents type 2 diabetes?}

- Intervention with lifestyle modification focused on adjustment of diet and exercise habits has been shown to be effective in preventing type 2 diabetes [13-15, 33-35] (grade A: 100\% agreement). 


\section{Q21-9 Does pharmacotherapy prevents type 2 diabetes?}

- Biguanides [36], $\alpha$-glucosidase inhibitors [37,38], and thiazolidinediones [39] are shown to be effective in preventing diabetes [in Japan, only voglibose has been covered by health insurance for use in patients with impaired glucose tolerance (IGT) who are considered to be at highrisk of cardiovascular disease] [40].

\section{Appendix}

\section{(1) Diabetes and cancer}

1. Report of the JDS/JCA Committee on Diabetes and Cancer

Given that there is a clear association between diabetes and the risk of cancer [1-9], experts from the Japan Diabetes Society (JDS) and the Japanese Cancer Association (JCA) launched a Joint Committee on Diabetes and Cancer, published a report in 2013 and provided its recommendations for physicians and other healthcare providers as well as for the general public, including patients [10].

\section{The Cancer Risk in Patients with Diabetes}

A pooled analysis of eight cohort studies conducted in Japan reported that the hazard ratio (HR) for the total cancer risk among patients with diabetes was 1.19 in comparison to those without, with the HR among men being 1.19 [95\% confidence interval (CI) 1.12-1.25] and that among women being 1.19 (95\% CI, 1.12-1.27) [11]. The mechanisms through which diabetes is likely to promote oncogenesis include insulin resistance and associated hyperinsulinemia, hyperglycemia, and chronic inflammation. However, whether diabetes is a causal risk factor for cancer remains to be elucidated.

\section{Glucose-lowering agents and cancer risk}

At present, the association between glucose-lowering agents and the cancer risk remains to be fully clarified. Thus, it is thought to be preferable that priority be given to maximizing the benefits of favorable glycemic control with these agents, with due consideration given to the warnings contained in their package inserts.

\section{(2) Diabetes and bone mineral metabolism}

1. The risk of bone fracture in patients with diabetes

The relative risk of proximal femoral fracture is increased three- to sevenfold in patients with type 1 diabetes and 1.3to 2.8 -fold in patients with type 2 diabetes.

Bone strength consists of two factors: bone mineral density (BMD) and bone quality.

The bone mineral metabolism in type 2 diabetes is characterized by increased BMD and impaired bone quality.

2. Anti-diabetic agents and bone mineral metabolism

A meta-analysis demonstrated that thiazolidinedione (TZD) treatment was associated with a 1.45-fold increase in the risk of fracture [12]. A further analysis indicated that TZDs were associated with a 2.23-fold increase in the risk of fracture in women but not in men [13].

There is no consensus on the risk of fracture associated with the use of insulin, DPP-4 inhibitors, GLP-1 receptor agonists, or metformin.

The US Food and Drug Administration (FDA) reported in its Drug Safety Communication that an SGLT-2 inhibitor, canagliflozin, has been associated with decreased BMD and an increased risk of fracture in comparison to a placebo [14].

3. The use of anti-osteoporosis agents in diabetes

The lumbar and femoral neck BMD have been reported to increase in patients with type 2 diabetes who receive alendronate [15].

\section{Pancreas/islet transplantation}

\section{Pancreas transplantation}

Pancreas transplantation has become available as a radical therapy for severe diabetes, particularly type 1 diabetes.

Pancreas transplantation is broadly divided into simultaneous pancreas and kidney transplantation (SPK), pancreasafter-kidney transplantation (PAK), and pancreas transplantation alone (PTA). SPK accounts for $>80 \%$ of all pancreas transplants performed in Japan and the rest of the world.

Data from the 210 brain-dead and non-heart beating donor pancreas transplants performed in Japan as of the end of 2014 demonstrated a 5-year graft survival rate of $95.8 \%$, with the 5-year pancreas and kidney survival rates of 70.4 and $89.2 \%$, respectively. 
The first living donor pancreas transplant in Japan was performed in January 2004 [16]; and as of the end of 2014, a total of 27 transplants had been performed.

\section{Islet transplantation}

Islet transplantation is a form of tissue transplantation that involves the injection of islets isolated from donor(s) into the recipient's portal vein and is thus less invasive than pancreas transplantation.

In Japan, 34 islet transplantation procedures (from nonheart beating donors) were performed in 18 patients (male, $n=5$; female, $n=13$ ) between 2004 and 2007; the procedures were performed in accordance with the Edmonton protocol [17]. Among these patients, 8, 4 and 6 patients received one, two and three transplants, respectively. One of the patients who received two transplants and two who received three transplants were shown to have achieved a temporary withdrawal of insulin therapy $[18,19]$.

The 1-, 2- and 3-year graft survival rates in these patients were $72.2,44.4$, and $22.2 \%$, respectively. The 1-year graft survival rate among those who received multiple transplants was $100 \%[18,19]$.

\section{(4) J-DOIT 1, 2, and 3, JDCP study and J-DREAMS}

- On the "Strategic Research Projects for Prevention of Diabetes"

In 2005, the Ministry of Health, Labor and Welfare (MHLW) of Japan launched a framework for the Health Frontier Strategic Plan as a large-scale MHLW research project. Thus, as a part of the project, the Strategic Research Projects for Prevention of Diabetes was initiated, consisting of three research themes (J-DOIT 1,2, and 3, respectively).

\section{- J-DOIT 1 (Japan Diabetes Outcome Intervention Trial 1)}

To prove that intensive lifestyle intervention is effective in preventing the onset of diabetes in patients at high-risk of developing diabetes in real-world settings (i.e., facilities offering health check-ups and health instruction services), a cluster randomized trial entitled, the "Japan Diabetes Outcome Intervention Trial 1 (J-DOIT 1)", was conducted between March 2007 and March 2012.

\section{- J-DOIT 2 (Japan Diabetes Outcome Intervention Trial 2)}

The "Japan Diabetes Outcome Intervention Trial 2 (J-DOIT 2)" was an interventional study intended to address how best decrease treatment and consultation interruptions by patients with type 2 diabetes.
The interventional measures implemented in the study included encouraging patients who were being treated by their family physicians to seek treatment/consultation, providing healthcare instructions, and providing their family physicians with assistance in their treatment/consultations. The results of the study demonstrated that treatment/consultation interruptions had been decreased by $63 \%$, suggesting that the interventional measures were significantly effective in decreasing treatment/consultation interruptions.

- J-DOIT 3 (the Japan Diabetes Optimal Integrated Treatment study for 3 major risk factors of cardiovascular diseases (J-DOIT 3)

The J-DOIT3 [Japan Diabetes Optimal Integrated Treatment study of three major risk factors for cardiovascular diseases (J-DOIT 3)] aimed to investigate whether or not integrated tight glycemic control, blood pressure control and lipid control may reduce the onset of macroangiopathy among patients with type 2 diabetes.

J-DOIT 3 was conducted from 2006 until March 2016. The study involved a total of 81 sites nationwide and enrolled a total of 2,532 type 2 diabetes patients who were considered to have a high-risk of developing macroangiopathy. The patients were randomly allocated to receive intensive therapy or conventional therapy.

\section{- JDCP study}

The JDCP study was a large-scale prospective observational study of Japanese patients with type 1 and type 2 diabetes. The study was conducted to identify the risk factors that patients with type 1 and 2 diabetes develop during follow-up.

The JDCP study enrolled a total of 6,338 patients of 40-74 years of age who were being treated at participating sites nationwide between June 2007 and November 2009. The primary endpoints of the study included the onset/progression of nephropathy, retinopathy, neuropathy, macroangiopathy, and periodontal disease.

\section{- J-DREAMS}

The Japan Diabetes comprehensive database project based on an advanced electronic medical record system (J-DREAMS) is a large-scale database project that was launched by the Japan Diabetes Society (JDS) and the National Center for Global Health and Medicine (NCGM).

Given that all JDS-qualified educational facilities for certificated diabetologists are participating and that hundreds of thousands of patients are expected to be registered, this study will be expected to show the control status of each parameter, the frequency of complications, and the 
correlations between complications and the glycemic control status or therapeutic agents in patients treated by certified diabetologists.

\section{References}

\section{Guideline for the diagnosis of diabetes mellitus}

1. Kosaka K,Akanuma Y, Goto Y, et al. Report of Committee on the classification and diagnostic criteria of diabetes mellitus.J Jpn Diabetes Soc. 1982;25:859-66 (in Japanese).

2. The Expert Committee on the Diagnosis and Classification of Diabetes Mellitus. Report of the expert committee on the diagnosis and classification of diabetes mellitus. Diabetes Care. 1997;20:1183-97.

3. World Health Organization. Report of a WHO consultation: definition, diagnosis and classification of diabetes mellitus and its complications. Part 1: diagnosis and classification of diabetes mellitus. Geneva: World Health Organization Department of Noncommunicable Disease Surveillance. 1999. http://www.staff .ncl.ac.uk/philip.home/who_dmc.htm.

4. Kuzuya T, Nakagawa S, Satoh J, et al. Report of the Committee of Japan Diabetes Society on the classification and diagnostic criteria of diabetes mellitus. J Jpn Diabetes Soc. 1999;42:385-404 (in Japanese).

5. Seino Y, Nanjo K, Tajima N. et al. Report of the Committee on the classification and diagnostic criteria of diabetes mellitus: The Committee of the Japan Diabetes Society on the diagnostic criteria of diabetes mellitus. Diabetol Int. 2010;1: 2.

6. Kadowaki T, Haneda M, Tominaga M, et al. Report of the Japan Diabetes Society's Committee on the diagnostic criteria for diabetes mellitus and glucose metabolism disorder-a new category of fasting plasma glucose values : "high-normal". J Jpn Diabetes Soc. 2008;51:281-3 (in Japanese).

7. Kawasaki E, Maruyama T, Imagawa A. et al. Diagnostic criteria for acute-onset type 1 diabetes mellitus (2012): Report of the Committee of Japan Diabetes Society on the Research of Fulminant and Acute-onset Type 1 Diabetes Mellitus. Diabetol Int. 2013;4:221.

8. Tanaka S, Ohmori M, Awata T. et al. Erratum to: Diagnostic criteria for slowly progressive insulin-dependent (type 1) diabetes mellitus (SPIDDM) (2012): report by the Committee on Slowly Progressive Insulin-Dependent (Type 1) Diabetes Mellitus of the Japan Diabetes Society. Diabetol Int. 2015;6:149.

9. Imagawa A., Hanafusa T., Awata T. et al. Report of the Committee of the Japan Diabetes Society on the Research of Fulminant and Acute-onset Type 1 Diabetes Mellitus: New Diagnostic Criteria of Fulminant Type 1 Diabetes Mellitus (2012). Diabetol Int. 2012;3:179-183.

10. Imagawa A, Hanafusa T.et al. A nationwide survey of fulminant type 1 diabetes mellitus J Jpn Soc Inten Med. 2013;102:18291835 (in Japanese)

\section{Goals and strategies for diabetes management}

1. United Kingdom Prospective Diabetes Study (UKPDS) Group. Intensive blood-glucose control with sulphonylureas or insulin compared with conventional treatment and risk of complications in patients with type 2 diabetes (UKPDS33). Lancet 1998;352:837-53 (level 1+).
2. Schauer PR, Bhatt DL, Kirwan JP, et al. Bariatric surgery versus intensive medical therapy for diabetes-3-year outcome. N Engl J Med. 2014;370:2002-13 (level. 1).

3. Sone H, Tanaka S, Tanaka S, et al. Serum level of triglycerides is a potent risk factor comparable to LDL cholesterol for coronary heart disease in Japanese patients with type 2 diabetes: subanalysis of the Japan Diabetes Complications Study (JDCS). J Clin Endocrinol Metab. 2011;96:3448-3456 (level 2).

\section{Medical nutrition therapy (MNT)}

1. Nakagawa Y, Ishikawa Y, Watanabe K, et al. Impact of the duration of diabetes and frequency of counseling on the effectiveness of dietitian-led medical nutrition therapy in patients with type 2 diabetes. J Jpn Diabetes Soc. 2014;57:813-9 (in Japanese) (level 3).

2. Pastors JG, Warshaw H, Daly A et al. The evidence for the effectiveness of medical nutrition therapy in diabetes management. Diabetes Care 2002;25:608-13 (level 3).

\section{Physical activity/exercise}

1. American Diabetes Association. Foundations of care and comprehensive medical evaluation. Sec. 3. In: Standards of Medical Care in Diabetes-2016. Diabetes Care 2016;39(Suppl 1):S23-35.

2. Marwick TH, Hordern MD, Miller T, et al. Exercise training for type 2 diabetes mellitus: impact on cardiovascular risk: a scientific statement from the American Heart Association. Circulation. 2009;119:3244-62.

3. Umpierre D, Ribeiro PA, Kramer CK et al: Physical activity advice only or structured exercise training and association with HbA1c levels in type 2 diabetes: a systematic review and metaanalysis. JAMA. 2011;305:1790-9 (level 1).

4. Boulé NG, Kenny GP, Haddad E, et al. Meta-analysis of the effect of structured exercise training on cardiorespiratory fitness in type 2 diabetes mellitus. Diabetologia. 2003;46:1071-81 (level 1).

5. Kelley GA, Kelley KS: Effects of aerobic exercise on lipids and lipoproteins in adults with type 2 diabetes: a meta-analysis of randomized-controlled trials. Public Health. 2007;121:643-55 (level 1).

6. Schwingshackl L, Missbach B, Dias S, et al. Impact of different training modalities on glycaemic control and blood lipids in patients with type 2 diabetes. a systematic review and network meta-analysis. Diabetologia. 2014;57:1789-97 (level 1).

7. Tonoli C, Heyman E, Roelands B, et al. Effects of different types of acute and chronic (training) exercise on glycaemic control in type 1 diabetes mellitus: a meta-analysis. Sports Med. 2012;42:1059-80 (level 3).

8. Kennedy A, Nirantharakumar K, Chimen M, et al. Does exercise improve glycaemic control in type 1 diabetes? a systematic review and meta-analysis. PLoS One 2013;8:e58861. https://doi. org/10.1371/journal.pone.0058861 (level 3).

9. Chiang JL, Kirkman MS, Laffel LM, et al. Type 1 diabetes sourcebook authors: type 1 diabetes through the life span: a position statement of the American Diabetes Association. Diabetes Care. 2014;37:2034-54.

\section{Treatment with glucose-lowering agents (excluding insulin)}

1. United Kingdom Prospective Diabetes Study (UKPDS) 13. Relative efficacy of randomly allocated diet, sulphonylurea, insulin, or metformin in patients with newly diagnosed non-insulin 
dependent diabetes followed for three years. BMJ. 1995;310:83-8 (level 1+).

2. Stratton IM, Adler AI, Neil HA, et al. Association of glycaemia with macrovascular and microvascular complications of type 2 diabetes (UKPDS 35): prospective observational study. BMJ. 2000;321:405-12 (level 2).

3. UK Prospective Diabetes Study (UKPDS) Group. Intensive bloodglucose control with sulphonylureas or insulin compared with conventional treatment and risk of complications in patients with type 2 diabetes (UKPDS 33). Lancet. 1998;352:837-53 (level $1+)$.

4. Inzucchi SE, Bergenstal RM, Buse JB, et al. Management of hyperglycemia in type 2 diabetes, 2015: a patient-centered approach: update to a position statement of the American Diabetes Association and the European Association for the Study of Diabetes. Diabetes Care. 2015;381:140-9.

5. UK Prospective Diabetes Study (UKPDS) Group. Effect of intensive blood-glucose control with metformin on complications in overweight patients with type 2 diabetes (UKPDS 34). Lancet. 1998;352:854-65 (level 1+).

6. Selvin E, Bolen S, Yeh HC, et al. Cardiovascular outcomes in trials of oral diabetes medications: a systematic review. Arch Intern Med. 2008;168:2070-80 (level 1+).

7. Zinman B, Wanner C, Lachin, JM, et al. Empagliflozin cardiovascular outcomes, and mortality in type 2 diabetes (EMPA-REG OUTCOME). N Engl J Med. 2015;373:2117-28 (level 1+).

8. Bennett WL, Wilson LM, Bolen S, et al. AHRQ comparative effectiveness reviews. oral diabetes medications for adults with type 2 diabetes: an update. Rockville (MD): Agency for Healthcare Research and Quality (US); 2011 (level 2).

9. Kaku K, Tajima N, Kawamori R, et al. Melbin Observational Research (MORE) study of metformin therapy in patients with type 2 diabetes mellitus. J Jpn Diabetes Soc. 2006;49:325-31 (in Japanese, level 2).

10. Meier C, Kraenzlin ME, Bodmer M, et al. Use of thiazolidinediones and fracture risk. Arch Intern Med. 2008;168:820-5 (level 3).

11. Loke YK, Singh S, Furberg CD. Long-term use of thiazolidinediones and fractures in type 2 diabetes: a meta-analysis. CMAJ. 2009;180:32-9 (level 2).

12. Home PD, Pocock SJ, Beck-Nielsen H, et al. Rosiglitazone evaluated for cardiovascular outcomes in oral agent combination therapy for type 2 diabetes (RECORD): a multicentre, randomised, open-label trial. Lancet. 2009;373:2125-35 (level 1+).

13. Colhoun HM, Livingstone SJ, Looker HC, et al. Hospitalised hip fracture risk with rosiglitazone and pioglitazone use compared with other glucose-lowering drugs. Diabetologia. 2012;55:2929_ 37 (level 3).

14. Nissen SE, Nicholls SJ, Wolski K, et al. Comparison of pioglitazone vs glimepiride on progression of coronary atherosclerosis in patients with type 2 diabetes: the PERISCOPE randomized controlled trial. JAMA. 2008;299:1561-73 (level 1).

15. Tajima N, Kadowaki T, Odawara M, et al. Addition of sitagliptin to ongoing glimepiride therapy in Japanese patients with type 2 diabetes over 52 weeks leads to improved glycemic control. Diabetol Int. 2011;2:32-44 (level 1).

16. Kadowaki T, Kondo K. Efficacy and safety of teneligliptin added to glimepiride in Japanese patients with type 2 diabetes mellitus: a randomized, double-blind, placebo-controlled study with an openlabel, long-term extension. Diabetes Obes Metab. 2014;16:418-25 (level 1).

17. Hermansen K, Kipnes M, Luo E, et al. Efficacy and safety of the dipeptidyl peptidase- 4 inhibitor, sitagliptin, in patients with type 2 diabetes mellitus inadequately controlled on glimepiride alone or on glimepiride and metformin. Diabetes Obes Metab. 2007;9:733-45 (level 1).
18. Iwakura T, Fujimoto K, Tahara Y, et al. A case of severe hypoglycemia induced by sitagliptin added to ongoing glimepiride therapy in patients with type 2 diabetes. J Jpn Diabetes Soc. 2010;53:505-8 (in Japanese, level 4).

19. Kadowaki T, Tajima N, Odawara M, et al. Efficacy and safety of sitagliptin add-on therapy in Japanese patients with type 2 diabetes on insulin monotherapy. Diabetol Int. 2013;4:160-72 (level 1).

20. Monami M, Dicembrini I, Mannucci E. Dipeptidyl peptidase-4 inhibitors and pancreatitis risk: a metaanalysis of randomized clinical trials. Diabetes Obes Metab. 2014;16:48-56 (level 1).

21. White WB, Cannon CP, Heller SR, et al. Alogliptin after acute coronary syndrome in patients with type 2 diabetes (EXAMINE). N Engl J Med. 2013;369:1327-35 (level 1+).

22. Scirica BM, Bhatt DL, Braunwald E, et al. Saxagliptin and cardiovascular outcomes in patients with type 2 diabetes mellitus (SAVOR). N Engl J Med. 2013;369:1317-26 (level 1+).

23. Green JB, Bethel MA, Armstrong PW, et al. Effect of sitagliptin on cardiovascular outcomes in type 2 diabetes (TECOS). N Engl J Med. 2015;373:232-42 (level 1+).

24. Kaku K, Rasmussen MF, Clauson P, et al. Improved glycaemic control with minimal hypoglycaemia and no weight change with the once-daily human glucagon-like peptide- 1 analogue liraglutide as add-on to sulphonylurea in Japanese patients with type 2 diabetes. Diabetes Obes Metab. 2010;12:341-7 (level 1).

25. Seino Y, Min KW, Niemoeller E, et al, Investigators EG-LAS. Randomized, double-blind, placebo-controlled trial of the oncedaily GLP-1 receptor agonist lixisenatide in Asian patients with type 2 diabetes insufficiently controlled on basal insulin with or without a sulfonylurea (GetGoal-L-Asia). Diabetes Obes Metab. 2012;14:910-7 (level 1).

26. Monami M, Dicembrini I, Nardini C, et al. Glucagon-like peptide-1 receptor agonists and pancreatitis: a meta-analysis of randomized clinical trials. Diabetes Res Clin Pract. 2014;103:269-75 (level 1).

27. Pfeffer MA, Claggett B, Diaz R. Lixisenatide in patients with type 2 diabetes and acute coronary syndrome (ELIXA). N Engl J Med. 2015;373:2247-57 (level 1+).

28. Monami M, Nardini C, Mannucci E. Efficacy and safety of sodium glucose co-transport- 2 inhibitors in type 2 diabetes: a meta-analysis of randomized clinical trials. Diabetes Obes Metab. 2014;16:457-66 (level 1).

29. Vasilakou D, Karagiannis T, Athanasiadou E, et al. Sodium-glucose cotransporter 2 inhibitors for type 2 diabetes: a systematic review and meta-analysis. Ann Intern Med. 2013;159:262-74 (level 1).

30. Bolinder J, Ljunggren O, Johansson L, et al. Dapagliflozin maintains glycaemic control while reducing weight and body fat mass over 2 years in patients with type 2 diabetes mellitus inadequately controlled on metformin. Diabetes Obes Metab. 2014;16:159-69 (level 1).

31. Charpentier G, Fleury F, Kabir M, et al. Improved glycaemic control by addition of glimepiride to metformin monotherapy in type 2 diabetic patients. Diabet Med. 2001;18:828-34 (level 1).

32. Moses R, Slobodniuk R, Boyages S, et al. Effect of repaglinide addition to metformin monotherapy on glycemic control in patients with type 2 diabetes. Diabetes Care. 1999;22:119-24 (level 1).

33. Van Gaal L, Maislos M, Schernthaner G, et al. Miglitol combined with metformin improves glycaemic control in type 2 diabetes. Diabetes Obes Metab. 2001;3:326-31 (level 1).

34. Einhorn D, Rendell M, Rosenzweig J, et al. Pioglitazone hydrochloride in combination with metformin in the treatment of type 2 diabetes mellitus: a randomized, placebo-controlled study. The Pioglitazone 027 Study Group. Clin Ther. 2000;22:1395-409 (level 1). 
35. Taskinen MR, Rosenstock J, Tamminen I, et al. Safety and efficacy of linagliptin as add-on therapy to metformin in patients with type 2 diabetes: a randomized, double-blind, placebo-controlled study. Diabetes Obes Metab. 2011;13:65-74 (level 1).

36. DeFronzo RA, Ratner RE, Han J et al. Effects of exenatide (exendin-4) on glycemic control and weight over 30 weeks in metformin-treated patients with type 2 diabetes. Diabetes Care. 2005;28:1092-100 (level 1).

37. Derosa G, Salvadeo SA, D'Angelo A, et al. Metabolic effect of repaglinide or acarbose when added to a double oral antidiabetic treatment with sulphonylureas and metformin: a double-blind, cross-over, clinical trial. Curr Med Res Opin. 2009;25:607-15 (level 1).

38. Scheen AJ, Tan MH, Betteridge DJ, et al. Long-term glycaemic control with metformin-sulphonylurea pioglitazone triple therapy in PROactive (PROactive 17). Diabet Med. 2009;26:1033-9 (level 3).

39. Lukashevich V, Prato SD, Araga M, et al. Efficacy and safety of vildagliptin in patients with type 2 diabetes mellitus inadequately controlled with dual combination of metformin and sulphonylurea. Diabetes Obes Metab. 2014;165:403-9 (level 1).

40. Kendall DM, Riddle MC, Rosenstock J, et al. Effects of exenatide (exendin-4) on glycemic control over 30 weeks in patients with type 2 diabetes treated with metformin and a sulfonylurea. Diabetes Care. 2005;285:1083-91 (level 1).

41. Wilding JP, Charpentier G, Hollander P, et al. Efficacy and safety of canagliflozin in patients with type 2 diabetes mellitus inadequately controlled with metformin and sulphonylurea: a randomised trial. Int J Clin Pract. 2013;6712:1267-82 (level 1).

\section{Insulin therapy}

1. The Diabetes Control and Complications Trial (DCCT) Research Group. Early worsening of diabetic retinopathy in the diabetes control and complications trial. Arch Ophthalmol. 1998;116:874 86 (level 1+).

2. Takahashi Y, Takayama S, Ito T, et al. Clinical features of eightysix diabetic patients with post-treatment painful neuropathy. J Jpn Diabetes Soc. 1998;41:165-70 (in Japanese, level 4).

3. United Kingdom Prospective Diabetes Study (UKPDS) Group. United Kingdom Prospective Diabetes Study 24: a 6-year, randomized, controlled trial comparing sulfonylurea, insulin, and metformin therapy in patients with newly diagnosed type 2 diabetes that could not be controlled with diet therapy. Ann Intern Med. 1998;128:165-75 (level 1).

4. The Diabetes Control and Complications Trial (DCCT) Research Group. The effect of intensive treatment of diabetes on the development and progression of long-term complications in insulindependent diabetes mellitus. N Engl J Med. 1993;329:977-86 (level 1+).

5. The Diabetes Control and Complications Trial (DCCT) Research Group. The effect of intensive diabetes therapy on measures of autonomic nervous system function in the Diabetes Control and Complications Trial (DCCT). Diabetologia. 1998;41:416-23 (level 1+).

6. Lawson ML, Gerstein HC, Tsui E, et al. Effect of intensive therapy on early macrovascular disease in young individuals with type 1 diabetes: a systematic review and meta-analysis. Diabetes Care. 1999;22(Suppl 2):B35-9 (level 1).

7. Nathan DM, Cleary PA, Backlund JY, et al. Intensive diabetes treatment and cardiovascular disease in patients with type 1 diabetes. N Engl J Med. 2005;353:2643-53 (level 1+).

8. Ohkubo Y, Kishikawa H, Araki E, et al. Intensive insulin therapy prevents the progression of diabetic microvascular complications in Japanese patients with non-insulin-dependent diabetes mellitus: a randomized prospective 6-year study. Diabetes Res Clin Pract. 1995;28:103-17 (level 1).

9. United Kingdom Prospective Diabetes Study (UKPDS) Group. Intensive blood-glucose control with sulphonylureas or insulin compared with conventional treatment and risk of complications in patients with type 2 diabetes (UKPDS 33). Lancet. 1998;352:837-53 (level 1+).

10. Shichiri M, Kishikawa H, Ohkubo Y, et al. Long-term results of the Kumamoto Study on optimal diabetes control in type 2 diabetic patients. Diabetes Care. 2000;23(Suppl 2):B21-9 (level 1).

11. Holman RR, Thorne KI, Farmer AJ, et al. Addition of biphasic, prandial, or basal insulin to oral therapy in type 2 diabetes. $\mathrm{N}$ Engl J Med. 2007;357:1716-30 (level 1).

12. Liebl A, Prager R, Binz K, et al. Comparison of insulin analogue regimens in people with type 2 diabetes mellitus in the PREFER study: a randomized controlled trial. Diabetes Obes Metab. 2009;11:45-52 (level 1).

13. Feinglos MN, Thacker CR, Lobaugh B, et al. Combination insulin and sulfonylurea therapy in insulin requiring type 2 diabetes mellitus. Diabetes Res Clin Pract. 1998;39:193-9 (level 1).

14. Wright A, Burden AC, Paisey RB, et al. Sulfonylurea inadequacy: efficacy of addition of insulin over 6 years in patients with type 2 diabetes in the UK Prospective Diabetes Study (UKPDS 57). Diabetes Care. 2002;25:330-6 (level 1).

15. Ozbek M, Erdogan M, Karadeniz M, et al. Preprandial repaglinide decreases exogenous insulin requirements and $\mathrm{HbA1c}$ levels in type 2 diabetic patients taking intensive insulin treatment. Acta Diabetol. 2006;43:148-51 (level 3).

16. De Luis DA, Aller R, Cuellar L, et al. Effect of repaglinide addition to NPH insulin monotherapy on glycemic control in patients with type 2 diabetes. Diabetes Care. 2001;24:1844-55 (level 3).

17. Yamada S, Watanabe M, Funae O, et al. Effect of combination therapy of a rapid-acting insulin secretagogue (glinide) with premixed insulin in type 2 diabetes mellitus. Intern Med. 2007;46:1893-7 (level 3).

18. Avilés-Santa L, Sinding J, Raskin P. Effects of metformin in patients with poorly controlled, insulin-treated type 2 diabetes mellitus: a randomized, double-blind, placebo-controlled trial. Ann Intern Med. 1999;131:182-8 (level 1).

19. Relimpio F, Pumar A, Losada F, et al. Adding metformin versus insulin dose increase in insulin-treated but poorly controlled type 2 diabetes mellitus: an open-label randomized trial. Diabet Med. 1998;15:997-1002 (level 1).

20. Yki-Järvinen H, Ryysy L, Nikkilä K, et al. Comparison of bedtime insulin regimens in patients with type 2 diabetes mellitus: a randomized, controlled trial. Ann Intern Med. 1999;130:389-96 (level 1).

21. Ponssen HH, Elte JW, Lehert P, et al. Combined metformin and insulin therapy for patients with type 2 diabetes mellitus. Clin Ther. 2000;22:709-18 (level 1).

22. Juntti-Berggren L, Pigon J, Hellström P, et al. Influence of acarbose on post-prandial insulin requirements in patients with type 1 diabetes. Diabetes Nutr Metab. 2000;13:7-12 (level 1).

23. Han A, Katoh S, Nemoto M, et al. Effect of combination therapy of premixtured $50 \mathrm{R}$ and voglibose in patients with type 2 diabetes. J Jpn Diabetes Soc. 2004;47:137-40 (in Japanese, level 1).

24. Schwartz S, Raskin P, Fonseca, V et al. Effect of troglitazone in insulin-treated patients with type II diabetes mellitus: Troglitazone and Exogenous Insulin Study Group. N Engl J Med. 1998;338:861-6 (level 1).

25. Mattoo V, Eckland D, Widel M, et al. Metabolic effects of pioglitazone in combination with insulin in patients with type 2 diabetes mellitus whose disease is not adequately controlled with insulin therapy: results of a six-month, randomized, doubleblind, prospective, multicenter, parallel-group study. Clin Ther. 2005;27:554-67 (level 1). 
26. Bhat R, Bhansali A, Bhadada S, et al. Effect of pioglitazone therapy in lean type 1 diabetes mellitus. Diabetes Res Clin Pract. 2007;78:349-54 (level 1).

27. Raskin $\mathrm{P}$, Rendell M, Riddle $\mathrm{MC}$, et al. A randomized trial of rosiglitazone therapy in patients with inadequately controlled insulin-treated type 2 diabetes. Diabetes Care. 2001;24:1226-32 (level 1).

28. Vilsbøll T, Rosenstock J, Yki-Järvinen H, et al. Efficacy and safety of sitagliptin when added to insulin therapy in patients with type 2 diabetes. Diabetes Obes Metab. 2010;12:167-77 (level 1).

29. Eng C, Kramer CK, Zinman B, Retnakaran R. Glucagon-like peptide-1 receptor agonist and basal insulin combination treatment for the management of type 2 diabetes: a systematic review and meta-analysis. Lancet. 2014;384:2228-34 (level 1).

30. Holman RR, Paul SK, Bethel MA, et al. 10-year follow-up of intensive glucose control in type 2 diabetes. N Engl J Med. 2008;359:1577-89 (level 1+).

31. The ACCORD Study Group. Long-term effects of intensive glucose lowering on cardiovascular outcomes. N Engl J Med. 2011;364:818-28 (level 1+).

\section{Diabetes Self-management education and support and education for the self-management of diabetes}

1. Tshiananga JK, Kocher S, Weber C, et al. The effect of nurse-led diabetes self-management education on glycosylated hemoglobin and cardiovascular risk factors: a meta-analysis. Diabetes Educ. 2012;38:108-23 (level 1).

2. Minet L, Moller S, Vach W, et al. Mediating the effect of self-care management intervention in type 2 diabetes: a meta-analysis of 47 randomised controlled trials. Patient Educ Couns. 2010;80:29-41 (level 1).

3. Deakin T, McShane CE, Cade JE. Group based training for selfmanagement strategies in people with type 2 diabetes mellitus. Cochrane Database Syst Rev. 2005:CD003417 (level 1).

4. Duke SA, Colagiuri S, Colagiuri R. Individual patient education for people with type 2 diabetes mellitus. Cochrane Database Syst Rev. 2009:CD005268 (level 1).

5. The Diabetes Control and Complications Trial Research Group. The effect of intensive treatment of diabetes on the development and progression of long-term complications in insulin-dependent diabetes mellitus. N Engl J Med. 1993;329:977-86 (level 1).

6. Karter AJ, Ackerson LM, Darbinian JA, et al. Self-monitoring of blood glucose levels and glycemic control: the Northern California Kaiser Permanente Diabetes registry. Am J Med. 2001;111:1-9 (level 3).

7. Avery L, Flynn D, van Wersch A, et al. Changing physical activity behavior in type 2 diabetes: a systematic review and meta-analysis of behavioral interventions. Diabetes Care. 2012;35:2681-9 (level 1).

8. Young RJ, Taylor J, Friede T, et al. Pro-active call center treatment support (PACCTS) to improve glucose control in type 2 diabetes: a randomized controlled trial. Diabetes Care. 2005;28:278-82 (level 1).

9. Katon WJ, Lin EH, Von Korff M, et al. Collaborative care for patients with depression and chronic illnesses. N Engl J Med. 2010;363:2611-20 (level 1).

10. Huang $\mathrm{Y}$, Wei $\mathrm{X}, \mathrm{Wu} \mathrm{T}$, et al. Collaborative care for patients with depression and diabetes mellitus: a systematic review and metaanalysis. BMC Psychiatry. 2013;13:260 (level 1).

\section{Diabetic retinopathy}

1. Klein R, Klein BE, Moss SE, et al. The Wisconsin Epidemiologic Study of Diabetic Retinopathy: IX. Fouryear incidence and progression of diabetic retinopathy when age at diagnosis is less than 30 years. Arch Ophthalmol. 1989;107:237-43 (level 2).

2. Klein R, Klein BE, Moss SE, et al. The Wisconsin Epidemiologic Study of Diabetic Retinopathy: X. Fouryear incidence and progression of diabetic retinopathy when age at diagnosis is 30 years or more. Arch Ophthalmol. 1989;107:244-9 (level 2).

3. Younis N, Broadbent DM, Vora JP, et al. Incidence of sight-threatening retinopathy in patients with type 2 diabetes in the Liverpool Diabetic Eye Study: a cohort study. Lancet. 2003;361:195-200 (level 2).

4. Misra A, Bachmann MO, Greenwood RH, et al. Trends in yield and effects of screening intervals during 17 years of a large UK community-based diabetic retinopathy screening programme. Diabet Med. 2009;26:1040-7 (level 2).

5. Diabetes Control and Complications Trial Research Group. The effect of intensive treatment of diabetes on the development and progression of long-term complications in insulin-dependent diabetes mellitus. N Engl J Med. 1993;329:977-86 (level 1+).

6. United Kingdom Prospective Diabetes Study (UKPDS) Group. Intensive blood-glucose control with sulphonylureas or insulin compared with conventional treatment and risk of complications in patients with type 2 diabetes (UKPDS 33). Lancet. 1998;352:837-53 (level 1+).

7. Chew EY, Ambrosius WT, Davis MD, et al. Effects of medical therapies on retinopathy progression in type 2 diabetes. $\mathrm{N}$ Engl $\mathrm{J}$ Med. 2010;363:233-44 (level 1+).

8. United Kingdom Prospective Diabetes Study (UKPDS) Group. Tight blood pressure control and risk of macrovascular and microvascular complications in type 2 diabetes: UKPDS 38. BMJ. 1998;317:703-13 (level 1+).

9. UK Prospective Diabetes Study (UKPDS) Group. Risks of progression of retinopathy and vision loss related to tight blood pressure control in type 2 diabetes mellitus: UKPDS 69. Arch Opthalmol. 2004;122:1631-40 (level 1+).

10. Keech AC, Mitchell P, Summanen PA, et al. Effect of fenofibrate on the need for laser treatment for diabetic retinopathy (FIELD study): a randomised controlled trial. Lancet. 2007;370:1687-97 (level 1+).

11. The Diabetic Retinopathy Study Research Group. Photocoagulation treatment of proliferative diabetic retinopathy: the second report of diabetic retinopathy study findings. Ophthalmology. 1978;85:82-106 (level 1).

12. Evans JR, Michelessi M, Virgili G. Laser photocoagulation for proliferative diabetic retinopathy. Cochrane Database Syst Rev. 2014;11:CD011234 (level 1).

13. Chew EY, Mills JL, Metzger BE, et al. Metabolic control and progression of retinopathy: the diabetes in early pregnancy study. National Institute of Child Health and Human Development Diabetes in Early Pregnancy Study. Diabetes Care. 1995;18:631-7 (level 2).

14. Soubrane G, Canivet J, Coscas G. Influence of pregnancy on the evolution of background retinopathy. Int Ophthalmol. 1985;8:249-55 (level 2).

15. Diabetes Control and Complications Trial Research Group. Effect of pregnancy on microvascular complications in the diabetes control and complications trial. Diabetes Care. 2000;23:1084-91 (level 3).

16. Rossing P, Hougaard P, Parving HH. Risk factors for development of incipient and overt diabetic nephropathy in type 1 diabetic patients: a 10-year prospective observational study. Diabetes Care. 2002;25:859-64 (level 2). 
17. Cheung N, Wang JJ, Klein R, et al. Diabetic retinopathy and the risk of coronary heart disease: the Atherosclerosis Risk in Communities Study. Diabetes Care. 2007;30:1742-6 (level 2).

18. Cheung N, Rogers S, Couper DJ, et al. Is diabetic retinopathy an independent risk factor for ischemic stroke? Stroke. 2007;38:398 401 (level 2).

19. Gerstein HC, Ambrosius WT, Danis R, et al. Diabetic retinopathy, its progression, and incident cardiovascular events in the ACCORD trial. Diabetes Care. 2013;36:1266-71 (level 3).

20. Kawasaki R, Tanaka S, Tanaka S, et al. Risk of cardiovascular diseases is increased even with mild diabetic retinopathy: the Japan diabetes complications study. Ophthalmology. 2013;120:574-82 (level 2).

\section{Diabetic nephropathy}

1. Katayama S, Moriya T, Tanaka S, et al. Low transition rate from normo- and low microalbuminuria to proteinuria in Japanese type 2 diabetic individuals: the Japan Diabetes Complications Study (JDCS). Diabetologia. 2011;54:1025-31 (level 2).

2. Ohkubo Y, Kishikawa H, Araki E, et al. Intensive insulin therapy prevents the progression of diabetic microvascular complications in Japanese patients with non-insulin-dependent diabetes mellitus: a randomized prospective 6-year study. Diabetes Res Clin Pract. 1995;28:103-17 (level 1).

3. Patel A, MacMahon S, Chalmers J, et al. Intensive blood glucose control and vascular outcomes in patients with type 2 diabetes. $\mathrm{N}$ Engl J Med. 2008;358:2560-72 (level 1+).

4. Shurraw S, Hemmelgarn B, Lin M, et al. Association between glycemic control and adverse outcomes in people with diabetes mellitus and chronic kidney disease: a population-based cohort study. Arch Intern Med. 2011;171:1920-7 (level 3).

5. UK Prospective Diabetes Study Group. Tight blood pressure control and risk of macrovascular and microvascular complications in type 2 diabetes: UKPDS 38. BMJ. 1998;317:703-13 (level 1+).

6. Makino H, Haneda M, Babazono T, et al. Prevention of transition from incipient to overt nephropathy with telmisartan in patients with type 2 diabetes. Diabetes Care. 2007;30:1577-8 (level 1+).

7. Lewis EJ, Hunsicker LG, Clarke WR, et al. Renoprotective effect of the angiotensin-receptor antagonist irbesartan in patients with nephropathy due to type 2 diabetes. N Engl J Med. 2001;345:8560 (level 1+).

8. Colhoun HM, Betteridge DJ, Durrington PN, et al. Effects of atorvastatin on kidney outcomes and cardiovascular disease in patients with diabetes: an analysis from the Collaborative Atorvastatin Diabetes Study (CARDS). Am J Kidney Dis. 2009;54:810-9 (level 1+).

9. Kimura S, Inoguchi T, Yokomizo H, et al. Randomized comparison of pitavastatin and pravastatin treatment on the reduction of urinary albumin in patients with type 2 diabetic nephropathy. Diabetes Obes Metab. 2012;14:666-9 (level 1+).

10. Haneda M, Kikkawa R, Sakai H, et al. Antiproteinuric effect of candesartan cilexetil in Japanese subjects with type 2 diabetes and nephropathy. Diabetes Res Clin Pract. 2004;66:87-95 (level 1).

11. Casas JP, Chua W, Loukogeorgakis S et al. Effect of inhibitors of the renin-angiotensin system and other antihypertensive drugs on renal outcomes: systematic review and meta-analysis. Lancet. 2005;366:2026-33 (level 1+).

12. Suckling RJ, He FJ, Macgregor GA. Altered dietary salt intake for preventing and treating diabetic kidney disease. Cochrane Database Syst Rev. 2010:CD006763 (level 1).

13. Imanishi M, Yoshioka K, Okumura M, et al. Sodium sensitivity related to albuminuria appearing before hypertension in type 2 diabetic patients. Diabetes Care. 2001;24:111-6 (level 2).
14. Hansen HP, Tauber-Lassen E, Jensen BR, et al. Effect of dietary protein restriction on prognosis in patients with diabetic nephropathy. Kidney Int. 2002;62:220-8 (level 1).

15. Koya D, Haneda M, Inomata S, et al. Long-term effect of modification of dietary protein intake on the progression of diabetic nephropathy: a randomised controlled trial. Diabetologia. 2009;52:2037-45 (level 1).

16. Kuriyama S, Tomonari $\mathrm{H}$, Yoshida $\mathrm{H}$, et al. Reversal of anemia by erythropoietin therapy retards the progression of chronic renal failure, especially in nondiabetic patients. Nephron. 1997;77:17685 (level 2).

17. Matsuo S, Imai E, Horio M, et al. Revised equations for estimated GFR from serum creatinine in Japan. Am J Kidney Dis. 2009;5:982-92.

18. Afkarian M, Sachs MC, Kestenbaum B, et al. Kidney disease and increased mortality risk in type 2 diabetes. J Am Soc Nephrol. 2013;24:302-8.

19. Horio M, Imai E, Yasuda Y. Collaborators Developing the Japanese Equation for Estimated GFR: GFR estimation using standardized serum cystatin C in Japan. Am J Kidney Dis. 2013;61:197-203.

\section{Diabetic neuropathy}

1. Hotta N, Toyoda R, et al. Diabetic neuropathy. Kanehara, Tokyo ;1996. p. 145-54 (in Japanese).

2. Boulton AJ, Vinik AI, Arezzo JC, et al. Diabetic neuropathies: a statement by the American Diabetes Association. Diabetes Care. 2005;28:956-62.

3. Tesfaye S, Chaturvedi N, Eaton SE, et al. Vascular risk factors and diabetic neuropathy. N Engl J Med 2005;352:341-50 (level 2).

4. The Diabetes Control and Complications Trial (DCCT) Research Group. The effect of intensive treatment of diabetes on the development and progression of long-term complications in insulindependent diabetes mellitus. N Engl J Med. 1993;329:977-86 (level 1+).

5. Ohkubo Y, Kishikawa H, Araki E, et al. Intensive insulin therapy prevents the progression of diabetic microvascular complications in Japanese patients with non-insulin-dependent diabetes mellitus: a randomized prospective 6-year study. Diabetes Res Clin Pract. 1995;28:103-17 (level 1).

6. Max MB, Culnane M, Schafer SC, et al. Amitriptyline relieves diabetic neuropathy pain in patients with normal or depressed mood. Neurology 1987;37:589-96 (level 1).

7. Freeman R, Durso-Decruz E, Emir B. Efficacy, safety, and tolerability of pregabalin treatment for painful diabetic peripheral neuropathy: findings from seven randomized, controlled trials across a range of doses. Diabetes Care. 2008;31:1448-54 (level 1).

8. Satoh J, Yagihashi S, Baba M, et al. Efficacy and safety of pregabalin for treating neuropathic pain associated with diabetic peripheral neuropathy: a 14 week, randomized, double-blind, placebo-controlled trial. Diabet Med. 2011;28:109-16 (level 1).

9. Pritchett YL, McCarberg BH, Watkin JG, et al. Duloxetine for the management of diabetic peripheral neuropathic pain: response profile. Pain Med. 2007;8:397-409 (level 1).

10. Yasuda H, Hotta N, Nakao K, et al. Superiority of duloxetine to placebo in improving diabetic neuropathic pain: results of a randomized controlled trial in Japan. J Diabetes Investig. 2011;2:132-9 (level 1).

11. Charles M, Soedamah-Muthu SS, Tesfaye S, et al. Low peripheral nerve conduction velocities and amplitudes are strongly related to diabetic microvascular complications in type 1 diabetes: the EURODIAB Prospective Complications Study. Diabetes Care. 2010;33:2648-53 (level 4). 
12. Tesfaye S, Boulton AJ, Dyck PJ et al. Diabetic neuropathies: update on definitions, diagnostic criteria, estimation of severity, and treatments. Diabetes Care. 2010;33:2285-2293

13 Japanese Study Group on Diabetic Neuropathy. Simplified diagnostic criteria and clinical staging of diabetic polyneuropathy. Peripheral Nerve. 2012;23:109-111

\section{Diabetic foot}

1. International Working Group on the Diabetic Foot (IWGDF). Guidance 2015. http://iwgdf.org/guidelines-2/.

2. Frykberg RG, Zgonis T, Armstrong DG, et al. Diabetic foot disorders: a clinical practice guideline (2006 revision). J Foot Ankle Surg. 2006;45:S1-66.

3. Resnick HE, Carter EA, Lindsay R, et al. Relation of lowerextremity amputation to all-cause and cardiovascular disease mortality in American Indians: the Strong Heart Study. Diabetes Care. 2004;27:1286-93 (level 2).

4. Krishinan S, Nash F, Baker N, et al. Reduction in diabetic amputations over 11 years in a defined UK population benefits of multidisciplinary team work and continuous prospective audit. Diabetes Care. 2008;31:99-101 (level 2).

5. Malone JM, Snyder M, Anderson G, et al. Prevention of amputation by diabetic education. Am J Surg. 1989;1508:520-4 (level 1).

6. Stratton IM, Adler A, Neil HAW, et al. Association of glycaemia with macrovascular and microvascular complications of type 2diabetes (UKPDS 35): prospective observational study. BMJ. 2000;321:405-12 (level 2).

7. Edmonds ME, Blundell MP, Morris ME, et al. Improved survival of the diabetic foot: the role of a specialized foot clinic. Q J Med. 1986;60:763-71 (level 4).

8. Armstrong DG, Bharara M, White $\mathrm{M}$, et al. The impact and outcomes of establishing an integrated interdisciplinary surgical team to care for the diabetic foot. Diabetes Metab Res Rev. 2012;28:514-8 (level 3).

9. Rooke TW, Hirsch AT, Misra S, et al. 2011 ACCF/AHA focused update of the guideline for the management of patients with peripheral artery disease (updating the 2005 guideline): a report of the American College of Cardiology Foundation/American Heart Association Task Force on Practice Guidelines. J Am Coll Cardiol. 2011;58:2020-45.

10. Lipsky BA, Berendt AR, Cornia PB, et al. 2012 Infectious Diseases Society of America clinical practice guideline for the diagnosis and treatment of diabetic foot infections. Clin Infect Dis. 2012;54:e132-73.

11. Holstein P, Ellitsgaard N, Olsen BB, et al. Decreasing incidence of major amputations in people with diabetes. Diabetologia. 2000;43:844-7 (level 4).

12. Valensi P, Girod I, Baron F, et al. Quality of life and clinical correlates in patients with diabetic foot ulcers. Diabetes Metab. 2005;31:263-71 (level 4).

13. Ribu L, Birkeland K, Hanestad BR, et al. A longitudinal study of patients with diabetes and foot ulcers and their health-related quality of life: wound healing and quality-of-life changes. J Diabetes Complications. 2008;22:400-7 (level 2).

14. Brownrigg JR, Davey J, Holt PJ, et al. The association of ulceration of the foot with cardiovascular and all cause mortality in patients with diabetes. Diabetologia. 2012;55:2906-12 (level 2).

\section{Diabetic macroangiopathy}

1. Gaede P, Vedel P, Larsen N, et al. Multifactorial intervention and cardiovascular disease in patients with type 2 diabetes. N Engl J Med. 2003;348:383-93 (level 1).
2. Miller ME, Williamson JD, Gerstein HC, et al, ACCORD Investigators. Effects of randomization to intensive glucose control on adverse events, cardiovascular disease, and mortality in older versus younger adults in the ACCORD Trial. Diabetes Care. 2014;37:634-43 (level 3).

3. Wing RR, Look AHEAD Research Group. Long-term effects of a lifestyle intervention on weight and cardiovascular risk factors in individuals with type 2 diabetes mellitus: four-year results of the Look AHEAD trial. Arch Intern Med. 2010;170:1566-75 (level 1).

4. Stratton IM, Adler AI, Neil HA, et al. Association of glycaemia with macrovascular and microvascular complications of type 2 diabetes (UKPDS 35): prospective observational study. BMJ. 2000;321:405-12 (level 2).

5. Adler AI, Stratton IM, Neil HA, et al. Association of systolic blood pressure with macrovascular and microvascular complications of type 2 diabetes (UKPDS 36): prospective observational study. BMJ. 2000;321:412-9 (level 2).

6. de Vries FM, Denig P, Pouwels KB et al. Primary prevention of major cardiovascular and cerebrovascular events with statins in diabetic patients: a meta-analysis. Drugs 2012;72:2365-73 (level 1).

7. de Vries FM, Kolthof J, Postma MJ, et al. Efficacy of standard and intensive statin treatment for the secondary prevention of cardiovascular and cerebrovascular events in diabetes patients: a meta-analysis. PLoS One. 2014;9:e111247 (level 1).

8. Simpson SH, Gamble JM, Mereu L, et al. Effect of aspirin dose on mortality and cardiovascular events in people with diabetes: a meta-analysis. J Gen Intern Med. 2011;26:1336-44 (level 2).

9. Baigent C, Blackwell L, Collins R, et al, Antithrombotic Trialists' (ATT) Collaboration. Aspirin in the primary and secondary prevention of vascular disease: collaborative meta-analysis of individual participant data from randomised trials. Lancet. 2009;373:1849-60 (level 1+).

\section{Diabetes and periodontitis}

1. Takahashi K, Nishimura F, Kurihara M, et al. Subgingival microflora and antibody responses against periodontal bacteria of young Japanese patients with type 1 diabetes mellitus. J Int Acad Periodontol. 2001;3:104-11 (level 3).

2. Morita I, Inagaki K, Nakamura F, et al. Relationship between periodontal status and levels of glycated hemoglobin. J Dent Res. 2012;91:161-6 (level 3).

3. Borgnakke WS, Ylöstalo PV, Taylor GW, et al. Effect of periodontal disease on diabetes: systematic review of epidemiologic observational evidence. J Periodontol. 2013;84:S135-52 (level 2).

4. Katagiri S, Nitta H, Nagasawa T, et al. Effect of glycemic control on periodontitis in type 2 diabetic patients with periodontal disease. J Diabetes Investig. 2013;4:320-5 (level 3).

5. Demmer RT, Jacobs DR, Desvarieux M. Periodontal disease and incident type 2 diabetes: results from the First National Health and Nutrition Examination Survey and its epidemiologic follow-up study. Diabetes Care. 2008;31:1373-9 (level 2).

6. Engebretson S, Kocher T. Evidence that periodontal treatment improves diabetes outcomes: a systematic review and meta-analysis. J Periodontol. 2013;84:S153-69 (level 1).

\section{Diabetes complicated by obesity (including metabolic syndrome)}

1. Matsuzawa Y, Sakata T, Ikeda Y, et al: Guidelines for the management of obesity disease 2006. 2006:1-91 (in Japanese). 
2. Saito Y, Shirai A, Nakamura M, et al: Diagnostic criteria for obesity disease 2011. 2011:1-78 (in Japanese).

3. Van Gaal L, Scheen A. Weight management in type 2 diabetes: current and emerging approaches to treatment. Diabetes Care. 2015;38:1161-72.

4.. Madigan CD, Aveyard P, Jolly K, et al. Regular self-weighing to promote weight maintenance after intentional weight loss: a quasirandomized controlled trail. J Public Health (Oxf). 2014;36:259_ 67 (level 2).

5. Ribaric G, Buchwald JN, McGlennon TW. Diabetes and weight in comparative studies of bariatric surgery vs conventional medical therapy: a systematic review and meta-analysis. Obes Surg. 2014;24:437-55 (level 2).

6. Committee on Diagnostic Criteria for Metabolic Syndrome. Metabolic syndrome: its definition and diagnostic criteria. J Jpn Soc Intern. 2005;94:794-9 (in Japanese).

\section{Hypertension associated with diabetes}

1. Kengne AP, Patel A, Barzi F, et al, Asia Pacific Cohort Studies Collaboration. Systolic blood pressure, diabetes and the risk of cardiovascular diseases in the Asia-Pacific region. J Hypertens. 2007;25:205-13 (level 2).

2. Patel A, MacMahon S, Chalmers J, et al. Effects of a fixed combination of perindopril and indapamide on macrovascular and microvascular outcomes in patients with type 2 diabetes mellitus (the ADVANCE trial): a randomised controlled trial. Lancet. 2007;370:829-40 (level 1+).

3. American Diabetes Association. Microvascular complications and foot care: standards of medical care in diabetes 2016. Diabetes Care. 2016;39:S72-80.

4. American Diabetes Association. Standards of medical care in diabetes 2010. Diabetes Care. 2010;30:S4-10.

5. Bangalore S, Kumar S, Lobach I, et al. Blood pressure targets in subjects with type 2 diabetes mellitus/impaired fasting glucose: observations from traditional and bayesian random-effects meta analyses of randomized trials. Circulation. 2011;123:2799-810 (level 1).

6. Eguchi K, Hoshide S, Ishikawa S, et al. Aggressive blood pressure-lowering therapy guided by home blood pressure monitoring improves target organ damage in hypertensive patients with type 2 diabetes/prediabetes. J Clin Hypertens. 2012;14:422-8 (level 3).

7. Cooper-DeHoff RM, Gong Y, Handberg EM, et al. Tight blood pressure control and cardiovascular outcomes among hypertensive patients with diabetes and coronary artery disease. JAMA. 2010;304:61-8 (level 3).

8. Haller H, Ito S, Izzo JL Jr, et al. Olmesartan for the delay or prevention of microalbuminuria in type 2 diabetes. $\mathrm{N}$ Engl $\mathrm{J}$ Med. 2011;364:907-17 (level 1+).

9. Heart Outcomes Prevention Evaluation Study Investigators. Effects of ramipril on cardiovascular and microvascular outcomes in people with diabetes mellitus: results of the HOPE study and MICRO-HOPE substudy. Lancet. 2000;355:253-9 (level 1+).

10. Lewis JB, Berl T, Bain RP, et al. Effect of intensive blood pressure control on the course of type 1 diabetic nephropathy: Collaborative Study Group. Am J Kidney Dis. 1999;34:809-17 (level 1).

\section{Dyslipidemia associated with diabetes}

1. Wang Y, Lammi-Keefe CJ, Hou L, et al. Impact of low-density lipoprotein cholesterol on cardiovascular outcomes in people with type 2 diabetes: a meta-analysis of prospective cohort studies. Diabetes Res Clin Pract. 2013;102:65-75 (level 2).
2. Turner RC, Millns H, Neil HA, et al. Risk factors for coronary artery disease in non-insulin dependent diabetes mellitus: United Kingdom Prospective Diabetes Study (UKPDS 23). BMJ. 1998;316:823-8 (level 3).

3. Sacks FM, Hermans MP, Fioretto P, et al. Association between plasma triglycerides and high-density lipoprotein cholesterol and microvascular kidney disease and retinopathy in type 2 diabetes mellitus: a global case-control study in 13 countries. Circulation. 2014;129:999-1008 (level 3).

4. Toth PP, Simko RJ, Palli SR, et al. The impact of serum lipids on risk for microangiopathy in patients with type 2 diabetes mellitus. Cardiovasc Diabetol. 2012;11:109-9 (level 3).

5.. Heilbronn LK, Noakes M, Clifton PM. Effect of energy restriction, weight loss, and diet composition on plasma lipids and glucose in patients with type 2 diabetes. Diabetes Care. 1999;22:889-95 (level 1).

6. Hartweg J, Perera R, Montori V, et al. Omega-3 polyunsaturated fatty acids (PUFA) for type 2 diabetes mellitus. Cochrane Database Syst Rev. 2008:CD003205-CD003205 (level 1).

7. Hayashino Y, Jackson JL, Fukumori N, et al. Effects of supervised exercise on lipid profiles and blood pressure control in people with type 2 diabetes mellitus: a meta-analysis of randomized controlled trials. Diabetes Res Clin Pract. 2012;98:349-60 (level 1).

8. Cholesterol Treatment Trialists C, Kearney PM, Blackwell L, et al. Efficacy of cholesterol-lowering therapy in 18,686 people with diabetes in 14 randomised trials of statins: a meta-analysis. Lancet. 2008;371:117-25 (level 1).

9. Colhoun HM, Betteridge DJ, Durrington PN, et al. Primary prevention of cardiovascular disease with atorvastatin in type 2 diabetes in the Collaborative Atorvastatin Diabetes Study (CARDS): multicentre randomised placebo-controlled trial. Lancet. 2004;364:685-96 (level 1+).

10. Keech A, Simes RJ, Barter P, et al. Effects of long-term fenofibrate therapy on cardiovascular events in 9795 people with type 2 diabetes mellitus (the FIELD study): randomised controlled trial. Lancet. 2005;366:1849-61 (level 1+).

11. Group AS, Ginsberg HN, Elam MB, et al. Effects of combination lipid therapy in type 2 diabetes mellitus. N Engl J Med. 2010;362:1563-74 (level 1+).

\section{Impaired glucose metabolism in pregnancy}

1. Ray JG, O'Brien TE, Chan WS. Preconception care and the risk of congenital anomalies in the offspring of women with diabetes mellitus: a meta-analysis. QJM. 2001;94:435-44 (level 2).

2. Falavigna M, Schmidt MI, Trujillo J, et al. Effectiveness of gestational diabetes treatment: a systematic review with quality of evidence assessment. Diabetes Res Clin Pract. 2012;98:396-405 (level 2).

3. Ekbom P, Damm P, Feldt-Rasmussen B, et al. Pregnancy outcome in type 1 diabetic women with microalbuminuria. Diabetes Care. 2001;24:1739-44 (level 2).

4. Metzger BE, Lowe LP, Dyer AR, HAPO Study Cooperative Research Group, et al. Hyperglycemia and adverse pregnancy outcomes. N Engl J Med. 2008;358:1991-2002 (level 2).

5. Chew EY, Mills JL, Metzger BE, et al. Metabolic control and progression of retinopathy. The Diabetes in Early Pregnancy Study. National Institute of Child Health and Human Development Diabetes in Early Pregnancy Study. Diabetes Care. 1995;18:631-7 (level 2).

6. Sanaka M,Minei S,Iwamoto Y. The allowance for pregnancy of women with diabetic nephropathy. J Jpn Soc Diabetes Pregnancy. 2006;6:127-35 (in Japanese, level 4).

7. Griffin ME, Coffey M, Johnson H, et al. Universal vs. risk factorbased screening for gestational diabetes mellitus: detection rates, 
gestation at diagnosis and outcome. Diabet Med. 2000;17:26-32 (level 2).

8. Ludwig DS, Currie J. The association between pregnancy weight gain and birthweight: a within-family comparison. Lancet. 2010;376:984-90 (level 2).

9. Langer O, Rodriguez DA, Xenakis EM, et al. Intensified versus conventional management of gestational diabetes. Am J Obstet Gynecol. 1994;170:1036-1046 (discussion 1046-1047, level 3).

10. Bellamy L, Casas JP, Hingorani AD, et al. Type 2 diabetes mellitus after gestational diabetes: a systematic review and metaanalysis. Lancet. 2009;373:1773-9 (level 1).

11. Hiramatsu Y, Haneda M, et al. The joint committee with the Japan Society of Diabetes and Pregnancy and the Japan Diabetes Society "An abnormal glucose metabolism during pregnancy and the standardization of its diagnostic criteria." J Jpn Diabetes Soc. 2015;58:801-803 (in Japanese)

\section{Pediatric/adolescent diabetes}

1. ISPAD Clinical Practice Consensus Guidelines for Pediatric and Adolescent Diabetes 2014. Nankodo, Tokyo. 2015.

2. Ascerini C, Craig ME, de Beaufort C, et al. ISPAD clinical practice consensus guidelines 2014 compendium. Introduction. Pediatr Diabetes. 2014;15(Suppl 20):1-3.

3. Craig ME, Jefferies C, Dabelea D, et al. ISPAD clinical practice consensus guidelines 2014 compendium. Definition, epidemiology, and classification of diabetes in children and adlescents. Pediatr Diabetes 2014;15(Suppl 20):4-17.

4. Ly TT, Maahs DM, Rewers A, et al. ISPAD clinical practice consensus guidelines 2014 compendium. Assessment and management of hypoglycemia in children and adolescents with diabetes. Pediatr Diabetes. 2014;15(Suppl 20):180-92.

5. Zeitler P, Fu J, Tandon N, et al. ISPAD clinical practice consensus guidelines 2014 compendium. Type 2 diabetes in the child and adolescent. Pediatr Diabetes. 2014;15(Suppl 20):26-46.

6. Urakami T, Suzuki J, Mugishima H, et al. Screening and treatment of childhood type 1 and type 2 diabetes mellitus in Japan. Pediatr Endocrinol Rev. 2012;10(Supple 1):51-61.

7. Rubio-Cabezas O, Hattersley AT, Njölstad PR, et al. ISPAD clinical practice consensus guidelines 2014 compendium. The diagnosis and management of monogenic diabetes in children and adolescents. Pediatr Diabetes. 2014;15(Suppl 20):47-64.

8. Sugihara S, Sasaki N, Kohno H, et al. Survey of current medical treatments for child-onset type 2 diabetes mellitus in Japan. Clin Pediatr Endocrinol. 2005;14:65-75 (level 4).

9. Rafiq M, Flanagan SE, Patch AM, et al. Effective treatment with oral sulfonylureas in patients with diabetes due to sulfonylurea receptor 1 (SUR1) mutations. Diabetes Care. 2008;31:204-9 (level 3).

10. Lange K, Swift P, Pankowska E, et al. ISPAD clinical practice consensus guidelines 2014 compendium. Diabetes education. Pediatr Diabetes. 2014;15(Suppl 20):77-85.

11. Delamater AM, de Wit M, McDarby V, et al. ISPAD clinical practice consensus guidelines 2014 compendium. Psychological issues. Pediatr Diabetes. 2014;15(Suppl 20):232-44.

12. Winkley K, Landau S, Eisler I, et al. Psychological interventions to improve glycaemic control in patients with type 1 diabetes: systematic review and meta-analysis of randomized controlled trials. BMJ. 2006;333:65-8 (level 1).

\section{Diabetes in older adults}

1. Ito H. Study to establish a treatment guideline for the elderly patients with diabetes mellitus. In: Research reports of the longevity sciences volume 3 . The Ministry of Health and Welfare of Japan. 1996. p. 309-11 (in Japanese, level 3).

2. Kuusisto J, Mykkänen L, Pyörälä K, et al. NIDDM and its metabolic control predict coronary heart disease in elderly subjects. Diabetes 1994;43:960-7 (level 2).

3. Cukierman T, Gerstein HC, Williamson JD. Cognitive decline and dementia in diabetes-systematic overview of prospective observational studies. Diabetologia. 2005;48:2460-9 (level 2).

4. Whitmer RA, Karter AJ, Yaffe K, et al. Hypoglycemic episodes and risk of dementia in older patients with type 2 diabetes mellitus. JAMA. 2009;301:1565-72 (level 2).

5. Kalyani RR, Tian J, Xue QL, et al. Hyperglycemia and incidence of frailty and lower extremity mobility limitations in older women. J Am Geriatr Soc. 2012;60:1701-7 (level 2).

6. Volpato S, Leveille SG, Blaum C, et al. Risk factors for falls in older disabled women with diabetes: the women's health and aging study. J Gerontol A Biol Sci Med Sci. 2005;60:1539-45 (level 2).

7. Johnston SS, Conner C, Aagren M, et al. Association between hypoglycaemic events and fall-related fractures in Medicarecovered patients with type 2 diabetes. Diabetes Obes Metab. 2012;14:634-43 (level 3).

8. Launer LJ, Miller ME, Williamson JD, et al. Effects of intensive glucose lowering on brain structure and function in people with type 2 diabetes (ACCORD MIND): a randomised open-label substudy. Lancet Neurol. 2011;10:969-77 (level 1).

9. Wannamethee SG, Shaper AG, Walker M. Changes in physical activity, mortality, and incidence of coronary heart disease in older men. Lancet. 1998;351:1603-8 (level 2).

10. Vita AJ, Terry RB, Hubert HB, et al. Aging, health risks, and cumulative disability. N Eng J Med 1998;338:1035-41 (level 2).

11. Japanese Geriatrics Society. Methodology for evaluation of cognitive function and diagnosis of dementia- a useful tool for geriatric care (in Japanese). http://www.jpn-geriat-soc.or.jp/tool/index .html.

12. Methodology for evaluation of ADL. Methodology for evaluation of cognitive function and diagnosis of dementia- a useful tool for geriatric care (in Japanese). http://www.jpn-geriat-soc.or.jp/tool/ index.html.

\section{Acute metabolic complications of diabetes, sick days, and infectious diseases}

1. Nyenwe EA, Kitabchi AE: Evidence-based management of hyperglycemic emergencies in diabetes mellitus. Diabetes Res Clin Pract. 2011;94:340-51.

2. Kitabchi AE, Umpierrez GE, Miles JM, et al. Hyperglycemic crises in adult patients with diabetes. Diabetes Care. 2009;32:1335-43.

3. Wolfsdorf J, Glaser N, Sperling MA. Diabetic ketoacidosis in infants, children, and adolescents. Diabetes Care. 2006;29:1150-9.

4. Jeffrey A, Kraut MD, Nicolaos E, et al. Lactic acidosis. N Engl J Med. 2014;371:2309-19.

5. Eppenga WL, Lalmohamed A, Geerts AF, et al. Risk of lactic acidosis or elevated lactate concentrations in metformin users with renal impairment: a population-based cohort study. Diabetes Care. 2014;37:2218-24 (level 2).

6. Silvio E, Inzucchi MD, Kasia J, et al. Metformin in patient with type 2 diabetes and kidney disease. JAMA. 2014;312:2668-75.

7. American Diabetes Association. Standards of medical care in diabetes-2016. Diabetes Care. 2016;39:S6-104.

8. . Seaquist ER, Anderson J, Childs B, et al. American Diabetes Association: Endocrine Society: hypoglycemia and diabetes: a report 
of a workgroup of the American Diabetes Association and the Endocrine Society. J Clin Endocrinol Metab. 2013;98:1845-59.

9. Nirmal J, Gregory M, Caputo GM, et al. Infections in patients with diabetes mellitus. N Engl J Med. 1999;341:1906-12.

10. NICE-SUGAR Study Investigators, Finfer S, Chittock DR, et al. Intensive versus conventional glucose control in critically ill patients. N Engl J Med. 2009;360:1283-97 (level 1+).

11. The Japanese society of Intensive Care Medicine Sepsis Registry. The Japanese Guidelines for the Management of Sepsis. 2013 (in Japanese).

12. Darren L, Dean TE, Sumit RM, et al. Effectiveness of influenza vaccination in working-age adults with diabetes: a populationbased cohort study. Thorax. 2013;68:658-63 (level 2).

13. Moberley SA, Holden J, Tatham DP, et al. Vaccines for preventing pneumococcal infection in adults. Cochrane Database Syst Rev. 2013:CD000422 (level 1).

14. Brink S, Joel D, Laffel L, et al. Sick day management in children and adolescents with diabetes. Pediatr Diabetes. 2014;15:193-202.

\section{Prevention of type 2 diabetes}

1. Heianza Y, Arase Y, Hsieh SD, et al. Development of a new scoring system for predicting the 5 year incidence of type 2 diabetes in Japan: the Toranomon Hospital Health Management Center Study 6 (TOPICS 6). Diabetologia 2012;55:3213-23 (level 3).

2. Sasai H, Sairenchi T, Irie F, et al. Development of a diabetes risk prediction sheet for specific health guidance. Nippon Koshu Eisei Zasshi. 2008;55:287-94 (in Japanese, level 3).

3. Doi Y, Ninomiya T, Hata J et al. Two risk score models for predicting incident type 2 diabetes in Japan. Diabet Med. 2012;29:107114 (level 2)

4. Kodama S, Horikawa C, Fujihara K, et al. Comparisons of the strength of associations with future type 2 diabetes risk among anthropometric obesity indicators, including waist-to-height ratio: a meta-analysis. Am J Epidemiol. 2012;176:959-69 (level 2).

5. Kodama S, Horikawa C, Yoshizawa S, et al. Body weight change and type 2 diabetes. Epidemiology. 2013;24:778-9 (level 2).

6. Kodama S, Horikawa C, Fujihara K, et al. Quantitative relationship between body weight gain in adulthood and incident type 2 diabetes: a meta-analysis. Obes Rev. 2014;15:202-14 (level 2).

7 . Harder T, Rodekamp E, Schellong K, et al. Birth weight and subsequent risk of type 2 diabetes: a metaanalysis. Am J Epidemiol. 2007;165:849-57 (level 2).

8. Whincup PH, Kaye SJ, Owen CG, et al. Birth weight and risk of type 2 diabetes: a systematic review. JAMA. 2008;300:2886-97 (level 2).

9. Sato KK, Hayashi T, Kambe H, et al. Walking to work is an independent predictor of incidence of type 2 diabetes in Japanese men: the Kansai Healthcare Study. Diabetes Care. 2007;30:2296-8 (level 2).

10. Jeon CY, Lokken RP, Hu FB, et al. Physical activity of moderate intensity and risk of type 2 diabetes: a systematic review. Diabetes Care. 2007;30:744-52 (level 2).

11. Grontved A, Pan A, Mekary RA, et al. Muscle-strengthening and conditioning activities and risk of type 2 diabetes: a prospective study in two cohorts of US women. PLoS Med. 2014;11:e1001587 (level 2).

12. Grontved A, Rimm EB, Willett WC, et al. A prospective study of weight training and risk of type 2 diabetes mellitus in men. Arch Intern Med. 2012;172:1306-12 (level 2).

13. Kosaka K, Noda M, Kuzuya T. Prevention of type 2 diabetes by lifestyle intervention: a Japanese trial in IGT males. Diabetes Res Clin Pract. 2005;67:152-62 (level 1).

14. Sakane N, Sato J, Tsushita K, et al. Prevention of type 2 diabetes in a primary healthcare setting: three year results of lifestyle intervention in Japanese subjects with impaired glucose tolerance. BMC Public Health. 2011;11:40 (level 1).

15. Saito T, Watanabe M, Nishida J, et al. Lifestyle modification and prevention of type 2 diabetes in overweight Japanese with impaired fasting glucose levels: a randomized controlled trial. Arch Intern Med. 2011;171:1352-60 (level 1).

16. Schulze MB, Schulz M, Heidemann C, et al. Fiber and magnesium intake and incidence of type 2 diabetes: a prospective study and meta-analysis. Arch Intern Med. 2007;167:956-65 (level 2).

17. Yao B, Fang H, Xu W, et al. Dietary fiber intake and risk of type 2 diabetes: a dose-response analysis of prospective studies. Eur J Epidemiol. 2014;29:79-88 (level 2).

18. Koppes LL, Dekker JM, Hendriks HF, et al. Moderate alcohol consumption lowers the risk of type 2 diabetes: a meta-analysis of prospective observational studies. Diabetes Care. 2005;28:719_ 25 (level 2).

19. Baliunas DO, Taylor BJ, Irving $\mathrm{H}$, et al. Alcohol as a risk factor for type 2 diabetes: a systematic review and meta-analysis. Diabetes Care. 2009;32:2123-32 (level 2).

20. Waki K, Noda M, Sasaki S, et al. Alcohol consumption and other risk factors for self-reported diabetes among middle-aged Japanese: a population-based prospective study in the JPHC study cohort I. Diabet Med. 2005;22:323-31 (level 2).

21. Seike N, Noda M, Kadowaki T. Alcohol consumption and risk of type 2 diabetes mellitus in Japanese: a systematic review. Asia Pac J Clin Nutr. 2008;17:545-51.

22. Ministry of Health, Labor and Welfare. Alcohol. Available from: http://www1.mhlw.go.jp/topics/kenko21_11/b5.html\#A51. (in Japanese).

23. Malik VS, Popkin BM, Bray GA, et al. Sugar-sweetened beverages and risk of metabolic syndrome and type 2 diabetes: a metaanalysis. Diabetes Care. 2010;33:2477-83 (level 2).

24. Greenwood DC, Threapleton DE, Evans CE, et al. Association between sugar-sweetened and artificially sweetened soft drinks and type 2 diabetes: systematic review and dose-response meta-analysis of prospective studies. 2014;Br J Nutr. 112:725-34 (level 2).

25. Kato M, Noda M, Inoue M, et al. Psychological factors, coffee and risk of diabetes mellitus among middle-aged Japanese: a population-based prospective study in the JPHC study cohort. Endocr J. 2009;56:459-68 (level 2).

26. Willi C, Bodenmann P, Ghali WA, et al. Active smoking and the risk of type 2 diabetes: a systematic review and meta-analysis. JAMA. 2007;298:2654-64 (level 2).

27. Yeh HC, Duncan BB, Schmidt MI, et al. Smoking, smoking cessation, and risk for type 2 diabetes mellitus: a cohort study. Ann Intern Med. 2010;152:10-17 (level 2).

28. Oba S, Noda M, Waki K, et al. Smoking cessation increases short-term risk of type 2 diabetes irrespective of weight gain: the Japan Public Health Center-based prospective study. PLoS One. 2012;7:e17061 (level 2).

29. Mezuk B, Eaton WW, Albrecht S, et al. Depression and type 2 diabetes over the lifespan: a meta-analysis. Diabetes Care. 2008;31 2383-90 (level 2).

30. Knol MJ, Twisk JW, Beekman AT, et al. Depression as a risk factor for the onset of type 2 diabetes mellitus. A meta-analysis. Diabetologia. 2006;49:837-45 (level 2).

31. Cappuccio FP, D'Elia L, Strazzullo P, et al. Quantity and quality of sleep and incidence of type 2 diabetes: a systematic review and meta-analysis. Diabetes Care. 2010;33:414-20 (level 2).

32. Gan Y, Yang C, Tong X, et al. Shift work and diabetes mellitus: a meta-analysis of observational studies. Occup Environ Med. 2015;72:72-8 (level 2).

33. Knowler WC, Fowler SE, Hamman RF, et al. 10-year follow-up of diabetes incidence and weight loss in the Diabetes Prevention Program Outcomes Study. Lancet. 2009;374:1677-86 (level 1). 
34. Lindstrom J, Peltonen M, Eriksson JG, et al. Improved lifestyle and decreased diabetes risk over 13 years: long-term follow-up of the randomised Finnish Diabetes Prevention Study (DPS). Diabetologia. 2013;56:284-93 (level 1).

35. Li G, Zhang P, Wang J et al. Cardiovascular mortality, all-cause mortality, and diabetes incidence after lifestyle intervention for people with impaired glucose tolerance in the Da Qing Diabetes Prevention Study: a 23-year follow-up study. Lancet Diabetes Endocrinol. 2014;2:474-80 (level 1).

36. Knowler WC, Barrett-Connor E, Fowler SE, et al. Reduction in the incidence of type 2 diabetes with lifestyle intervention or metformin. N Engl J Med. 2002;346:393-403 (level 1).

37. Chiasson JL, Josse RG, Gomis R, et al. Acarbose for prevention of type 2 diabetes mellitus: the STOPNIDDM randomised trial. Lancet. 2002;359:2072-7 (level 1).

38. Padwal R, Majumdar SR, Johnson JA, et al. A systematic review of drug therapy to delay or prevent type 2 diabetes. Diabetes Care. 2005;28:736-44 (level 2).

39. DeFronzo RA, Tripathy D, Schwenke DC, et al. Pioglitazone for diabetes prevention in impaired glucose tolerance. N Engl J Med. 2011;364:1104-15 (level 1).

40. Kawamori R, Tajima N, Iwamoto Y, et al. Voglibose for prevention of type 2 diabetes mellitus: a randomised, double-blind trial in Japanese individuals with impaired glucose tolerance. Lancet. 2009;373:1607-14 (level 1).

\section{Appendix}

1. Bonovas S, Filioussi K, Tsantes A. Diabetes mellitus and risk of prostate cancer: a meta-analysis. Diabetologia. 2004;47:1071-1078.

2. Friberg E, Orsini N, Mantzoros CS et al. Diabetes mellitus and risk of endometrial cancer: a meta-analysis. Diabetologia. 2007;50:1365-1374.

3. Huxley R, Ansary-Moghaddam A, de Gonzalez AB et al. Type-II diabetes and pancreatic cancer: a meta-analysis of 36 studies. $\mathrm{Br}$ J Cancer. 2005;92:2076-2083.

4. Kasper JS, Giovannucci E. A meta-analysis of diabetes mellitus and the risk of prostate cancer. Cancer Epidemiol Biomarkers Prev. 2006; 15:2056-2062.

5. Larsson SC, Orsini N, Wolk A. Diabetes mellitus and risk of colorectal cancer: a meta-analysis. J Natl Cancer Inst. 2005;97:1679-1687.

6. Larsson SC, Orsini N, Brismar K et al. Diabetes mellitus and risk of bladder cancer: a meta-analysis. Diabetologia. 2006;49:2819-2823.
7. Larsson SC, Mantzoros CS, Wolk A. Diabetes mellitus and risk of breast cancer: a meta-analysis. Int J Cancer. 2007;121:856-862.

8. Noto H, Osame K, Sasazuki T, Noda M. Substantially increased risk of cancer in patients with diabetes mellitus: a systematic review and meta-analysis of epidemiologic evidence in Japan. J Diabetes Complications. 2010;24:345-353.

9. Noto H, Tsujimoto T, Sasazuki T et al. Significantly increased risk of cancer in patients with diabetes mellitus: a systematic review and meta-analysis. Endocr Pract. 2011;17:616-628.

10. Kasuga M, Ueki K, Tajima $\mathrm{N}$ et al. Report of the JDS/JCA Joint Committee on Diabetes and Cancer. Diabetol Int 2013; 2:81-96.

11. Sasazuki S, Charvat H, Hara A et al. Diabetes mellitus and cancer risk: pooled analysis of eight cohort studies in Japan. Cancer Sci. 2013;104:1499-1507.

12. Loke YK, Singh S, Furberg CD. Long-term use of thiazolidinediones and fractures in type 2 diabetes: a meta-analysis. CMAJ. 2009;180:32-39.

13. Ad hoc committee for Japanese 2015 guidelines for prevention and treatment of osteoporosis, Chairman Hajime Orim. Japanese 2015 guidelines for prevention and treatment of osteoporosis. Life Science Publishing Co., Ltd.; 2015. (in Japanese)

14. FDA Drug Safety Communication: FDA revises label of diabetes drug canagliflozin (Invokana, Invokamet) to include updates on bone fracture risk and new information on decreased bone mineral density. http://www.fda.gov/Drugs/DrugSafety/ucm461449.htm/. Accessed 28 Feb 2018.

15. Keegan TH, Schwartz AV, Bauer DC et al. Effect of alendronate on bone mineral density and biochemical markers of bone turnover in type 2 diabetic women: the fracture intervention trial. Diabetes Care. 2004;27:1547-1553.

16. Kenmochi T, Asano T, Saigo K et al. The first case of simultaneous pancreas-kidney transplant from living donor in our country. Japanese J. of Transplant. 2005;40:466-472. (in Japanese)

17. Fukao K, Otsuka M, Iwasaki $\mathrm{H}$ et al. A case of simultaneous whole pancreas and kidney allotransplantation. Japanese J. of Transplant. 1986;21:331-340. (in Japanese)

18. Saito T, Gotoh M, Satomi S et al. Islet transplantation using donors after cardiac death: report of the Japan Islet Transplantation Registry. Transplantation. 2010;90:740-747.

19. The Japanese Pancreas and Islet Transplantation Association. Islet transplantation in Japan_- Report from Japanese Islet Transplantation Registry__. Japanese J. of Transplant. 2014;49:292_ 297. (in Japanese). 